NBER WORKING PAPER SERIES

\title{
WHY IS PRODUCTIVITY CORRELATED WITH COMPETITION?
}

\author{
Matthew Backus \\ Working Paper 25748 \\ http://www.nber.org/papers/w25748
NATIONAL BUREAU OF ECONOMIC RESEARCH
1050 Massachusetts Avenue
Cambridge, MA 02138
April 2019

This is a revised version of the first chapter of my dissertation; the original version is dated November 11, 2011. I am grateful to my advisors Daniel Ackerberg, Jeremy Fox, Francine Lafontaine, Natalia Lazzati, and Scott Page for their encouragement and guidance. Thanks also to Jim Adams, Allan Collard-Wexler, Ying Fan, John Haltiwanger, Panle Jia Barwick, Kai-Uwe Kühn, Shawn Klimek, Jagadeesh Sivadasan, Chad Syverson, and numerous seminar participants for helpful comments and suggestions. All remaining errors are my own. This paper was written while I was a Special Sworn Status researcher of the US Census Bureau at the University of Michigan Research Data Center. Any opinions and conclusions expressed herein are those of the author and do not necessarily represent the views of the U.S. Census Bureau or the National Bureau of Economic Research. All results have been reviewed to ensure that no confidential information is disclosed.

NBER working papers are circulated for discussion and comment purposes. They have not been peer-reviewed or been subject to the review by the NBER Board of Directors that accompanies official NBER publications.

(C) 2019 by Matthew Backus. All rights reserved. Short sections of text, not to exceed two paragraphs, may be quoted without explicit permission provided that full credit, including (C) notice, is given to the source. 
Why is Productivity Correlated with Competition?

Matthew Backus

NBER Working Paper No. 25748

April 2019

JEL No. L22,L23,L25,L61

\begin{abstract}
$\underline{\text { ABSTRACT }}$
The correlation between productivity and competition is an oft-observed but ill-understood result. Some suggest that there is a treatment effect of competition on measured productivity, e.g. through a reduction of managerial slack. Others argue that greater competition makes unproductive establishments exit by reallocating demand to their productive rivals, raising observed average productivity via selection. I study the ready-mix concrete industry and offer three perspectives on this ambivalence. First, using a standard decomposition approach, I find no evidence of greater reallocation of demand to productive plants in more competitive markets. Second, I model the establishment exit decision and construct a semi-parametric selection correction to quantify the empirical significance of treatment and selection. Finally, I use a grouped IV quantile regression to test the distributional predictions of the selection hypothesis. I find no evidence for greater selection or reallocation in more competitive markets; instead, all three results suggest that measured productivity responds directly to competition. Potential channels include specialization and managerial inputs.
\end{abstract}

Matthew Backus

Graduate School of Business

Columbia University

3022 Broadway, Uris Hall 619

New York, NY 10027

and NBER

matthew.backus@columbia.edu 


\section{Introduction}

There is a perennial paper in the productivity literature which presents the following result, updated for contemporary innovations in attitudes towards data and econometrics: firms that are in more competitive markets are more efficient. This correlation has been identified cross-sectionally across industries (Caves and Barton, 1990; Green and Mayes, 1991), and in panels as well (Nickell, 1996; Hay and Liu, 1997); in the US (Dertouzos et al., 1989) and abroad (Porter, 1990); papers in the trade literature have identified this result using policy changes (Pavcnik, 2002, Sivadasan, 2009), and the correlation remains stark in industry-level studies (Graham et al., 1983; Olley and Pakes, 1996; Fabrizio et al., 2007).

The existence of a positive correlation between competition and productivity is of first-order significance for several reasons. The most salient is the possibility of productive efficiencies of competition, which are, as Williamson (1968) observed in the setting of merger evaluation, infra-marginal and therefore prima fascia larger than allocative efficiencies. The potential for such gains could motivate competition policy. Second, the correlation is relevant to recent work on international trade following Melitz (2003), which highlighted productive efficiencies as an important source of gains from trade liberalization. Third and finally, from a business economics standpoint, the correlation offers some leverage on the productivity dispersion puzzle: that establishments in the same industry with the same inputs often produce vastly different quantities of output.

Though the existence of a positive correlation between competition and productivity bears on fundamental questions, the mechanism generating it remains controversial. I focus on two leading hypotheses: first, that competition has a direct causal effect on productivity and second, that the correlation is driven by selective attrition of low-productivity establishments in more competitive markets; respectively, the treatment effect and the selection effect. The treatment effect hypothesis says that competition behaves as if it were an input of the production function. Therefore, if one could, ceteris paribus, transplant a firm from a lessto a more competitive market, the treatment effect hypothesis implies that it would exhibit an increase in measured productivity. The language "treatment effect" here stands in for real economic phenomena within the firm; in fact, there exists several models consistent with such an effect of competition on productivity - more competitive markets may give firms better incentives to monitor managers or invest in productivity enhancements, or they may create positive informational externalities. Complementary to this, a number of historical studies have documented examples where competition — or the threat of competition - 
spurred reorganization, renegotiation of contracts, and higher productivity.

The second hypothesis, the selection effect, operates though selective attrition of low-productivity establishments in highly competitive markets; to wit, it conjectures that market selection on productivity is more aggressive in more competitive markets. Because observation is contingent on survival, this implies that the econometrician will observe a correlation between productivity and competition among surviving plants, even when there is no treatment effect of competition on productivity. This hypothesis is corollary to an idea that has become central in models of industry dynamics and trade liberalization: that more competitive markets reallocate demand from low productivity establishments to high productivity ones.

The main contribution of this paper is to construct a way to test how competition affects productivity. Rather than looking at a handful of changes over time, it uses variation across hundreds of markets in the ready-mixed concrete industry. And rather than using point estimates from an accounting decomposition, it uses the covariance of plant-level productivity estimates and the extent of competition in the local market. This allows me to show how these two hypotheses - the treatment effect and the selection effect of competition - are separable in the data. I develop two alternative approaches, both of which yield the same conclusion.

First, I use an explicit model of the establishment's exit decision problem to derive a semiparametric selection correction that quantifies the relative contributions of both hypotheses. The estimator does not require parametric assumptions on demand; instead, the key identifying assumptions are the timing of play and the exogeneity of innovations in establishmentlevel productivity types. In this sense identification in this approach is similar to that in papers on semi-parametric production function estimation $]^{1}$

The second empirical strategy I use is a grouped instrumental variables quantile regression approach at the market level; this allows me to identify the marginal effect of competition on productivity at all quantiles of the productivity distribution. I use this to test the hypothesis, implied by selective attrition of low-productivity establishments, that the effect is driven by changes in the left tail of the productivity distribution. In contrast with the first identification strategy, this approach requires no assumptions on the establishment's decision problem beyond the existence of a threshold exit strategy; however, its conclusions are correspondingly less weaker: besides its intuitive graphical appeal, it can only offer

\footnotetext{
${ }^{1}$ In particular, my identification result depends on timing assumptions related to those advanced in Olley and Pakes (1996); Levinsohn and Petrin (2003), and Ackerberg et al. (2015).
} 
evidence that selection is not the exclusive mechanism.

The natural setting for applying these methods is the ready-mix concrete industry. An important challenge in studying the relationship between competition and productivity is finding sufficient cross-sectional variation in competitive structure at the market level. Though rich data exists for most manufacturing industries, low transportation costs make them global in market definition. This unfortunate fact leaves the econometrician with only cross-industry or time series variation in market structure, both of which are suspect. In contrast, idiosyncratically high transportation costs make markets for ready-mix concrete fundamentally local, which I exploit to construct geographically defined markets that yield within-industry, crossmarket variation. In addition, the availability of homogenous output measures in physical, rather than revenue, terms allows me to estimate physical productivity without knowing prices. Following the language of Foster et al. (2008), I am therefore able to use TFPQ ( $\mathrm{Q}$ for quantity) rather TFPR ( $\mathrm{R}$ for revenues). This averts the issue raised in Klette and Giliches (1996), that revenue-based output measures include equilibrium markups and are therefore mechanically correlated with competition, which would be particularly problematic for my application.

My results show that, in ready-mix concrete, the correlation between competition and productivity is driven by the treatment effect hypothesis, i.e. within-firm changes in productivity in response to competitive conditions. I find no evidence that the selection effect hypothesis drives productivity changes. I explore this further using a standard decomposition of output-weighted productivity at the market level that offers insight on reallocation. I show that market-level reallocation, as proxied by the productivity-share covariance term, is unresponsive to exogenous changes in competition, which may explain the absence of a selection effect. Note that this does not imply an absence of market selection altogether. Prior work on ready-mix concrete has already documented a negative relationship between establishment productivity and exit.2 My results show that the degree of market selection on physical productivity is not driven by differences in competition - more precisely, not enough to explain the observed correlation between competition and productivity.

These results suggest productive directions for future research. If reallocation and selection does not drive the correlation, what are firms doing differently in more competitive markets? I am able to offer some limited evidence: the data here suggest greater specialization, greater managerial inputs, and are inconsistent with a story of capacity utilization. Taken

\footnotetext{
${ }^{2}$ See Foster et al. (2008) and Collard-Wexler (2011), as well as a prior draft of this paper.
} 
together, this suggests that, in light of the growing policy interest in understanding the effects of concentration and market power, a productive direction is to look within the firm, and not exclusively at the allocative and re-allocative effects of competition. I also offer some evidence, in Section 6.3, that this generalizes beyond ready-mix concrete. Within-firm adjustment mechanisms may be first-order important for understanding productive efficiencies from competition, gains from trade, and establishment-level productivity dispersion.

Section 2 briefly summarizes related literature to motivate the question. Section 3 describes the ready-mix concrete industry, the data used, and measurement issues associated with studying productivity, spatially defined markets, and competition indexes. Section 4 contains the reduced-form results: I replicate the standard finding of a correlation between productivity and competition, introduce my IV strategy, and consider the role of "reallocation." Section 5 contains the main methodological contributions of the paper: the structurallymotivated selection correction and the quantile IV results. In Section 6 I address several first-order robustness concerns and offer what evidence I can on mechanisms. Section 7 concludes.

\section{Related Literature}

This paper draws on several literatures which I summarize in three parts. The first set of papers elaborates the treatment effect hypothesis: this includes empirical documentation and a theoretical literature offering a rigorous foundation. The second set of papers is related to the empirical and theoretical basis of the selection effect. Finally, I briefly describe a large and celebrated literature studying productivity using establishment-level data, with special attention to ready-mix concrete.

\subsection{Treatment Effect}

The idea that productivity is directly related to competition has a long and controversial history in economics. Concluding a discussion of contemporary developments in the theory of monopoly, Hicks (1935) foreshadows the notion of managerial slack when he notes that perhaps "the best of all monopoly rents is a quiet life." Again in Leibenstein (1966) the idea emerges under the title "X-efficiency:" intuitively and empirically — but inexplicably — it 
seems as if firms in more competitive markets are more motivated to reduce costs. This particular incarnation was assailed in Stigler (1976), which objected to the substitution of "motivation" for sound economic reasoning ${ }^{3}$ Indeed, at that time it was difficult to reconcile the empirical phenomenon with optimal choice theory: why would a monopolist have any less incentive to reduce costs?

Subsequent theoretical developments in games with asymmetric information and industry dynamics offered myriad answers to that question. If imperfect monitoring creates a wedge between optimal production and the the second-best (the optimum conditional on incomplete contracts) the relevant question becomes how that wedge depends on competitive conditions in the market. A small literature on principal-agent problems with multiple players following Holmström (1982) develops this idea- if the noise with which the principal observes agents' behavior is correlated across agents, adding an additional agent has informational externalities that, in the limit, allow the principal to extract optimal effort. In the context of productive efficiencies of competition, owners may be able to more effectively monitor managers when they can compare their performance against that of other firms in the market. Alternatively, Schmidt (1997) proposes risk of liquidation as a way to re-align incentives of the agent; if competitive firms are more likely to go bankrupt, there is less room for shirking. Raith (2003) offers another approach. That paper considers incentives to invest in cost reduction, and shows two competing effects of competition- a business-stealing effect and a scale effect. The former implies that increased substitutability generates more incentive to invest, while operating on a smaller scale in a thicker market weakens those incentives. The stark result of that paper is that in the long run - i.e. allowing for equilibrium entry and exit - the business stealing effect of competition dominates the scale effect, assuring a positive correlation between competition and productivity.

The intuition that competition can drive within-firm productivity changes has been documented in several industry-level studies. Schmitz $(2002,2005)$ show how increased competition drove greater labor productivity in the US Iron Ore industry. In cement, which saw dramatic changes due to import penetration in the 1980's, this took the form of renegotiation of work rules and contracts at the plant level, as documented in Dunne et al. (2010). This literature is surveyed in more detail in Holmes and Schmitz (2010).

\footnotetext{
${ }^{3}$ See Perelman (2011) for a summary of the Leibenstein-Stigler debate concerning X-Efficiency.
} 


\section{$2.2 \quad$ Selection Effect}

The selection effect hypothesis is a theoretical prediction of industry dynamics models that descend from Hopenhayn (1992). Establishments in this framework make a decision of whether to stay in the market or exit, and they do so based on their idiosyncratic cost type as well as the degree of competition they face from other firms. Those establishments may exit if their productivity type is such that the present discounted value of remaining is lower than their scrap value. The stationary distribution of firms' types, then, is the ergodic distribution generated by equilibrium entry and left-truncation as low-productivity firms exit. These models have been successful at modeling turnover and market size (Asplund and Nocke, 2006), barriers to entry (Barseghyan and DiCecio, 2011), and have been famously extended to capture trade liberalization and establishments' decisions to export (Melitz, $2003)$.

These models are also the basis of the selection effect hypothesis, which claims that the equilibrium exit threshold increases as a market becomes more competitive. As the threshold rises, the selected set of surviving firms is on average more productive, generating a correlation between competition and productivity without resort to a treatment effect. This prediction depends on a key assumption on stage-game profits, which has been called "reallocation:" that more competitive markets are better at reallocating demand from less- to more-productive firms. This assumption is standard in industry dynamics models, though it often takes different forms..$^{4}$ In the empirical literature, this reallocation mechanism has been an important channel for productivity growth since Olley and Pakes (1996), and Boone (2008) goes still further, arguing that reallocation is constitutive of competition, not merely related to it. In Appendix B I offer a simple entry model to illustrate the subtle and important relationship between reallocation and selection and in Section 4.2 I test for the reallocation mechanism in ready-mix concrete directly.

\subsection{Establishment-Level Productivity}

The availability of comprehensive establishment-level input and output data sparked a vibrant literature on productivity analysis. Early contributions in this literature are reviewed

\footnotetext{
${ }^{4}$ The assumption is most transparent in Asplund and Nocke (2006), where it takes the form of a logsupermodularity assumption on the profit function in type and market size, however it also follows from the parametric assumptions in Syverson (2004a) and Melitz and Ottaviano (2008). It is also related to the multiplicative separability assumption, Condition U2, of Hopenhayn (1992)
} 
in Bartelsman and Doms (2000). Subsequently Foster et al. (2008) studied the relationship between demand, productivity, and exit. They find that even in markets with homogenous products, idiosyncratic demand shocks are an important determinant of firm survival. A recent contribution by Bloom et al. (2016) revisits the trade shock literature using firmlevel data from Europe in the context of China's entry into the WTO and finds substantial productivity effects, but through an different mechanism: technological upgrading and the release of "trapped" factors of production, with a distinctly Ricardian flavor.

An important subset of this literature has focused on ready-mix concrete. In particular, this paper builds on the pioneering work of Syverson (2004a), which studied the negative correlation of productivity dispersion with competition. That paper sidestepped the question of mechanisms and assumes selection; this one steps back re-considers the treatment effect. 5 Also closely related is Collard-Wexler (2011), which studies the relationship between productivity dispersion and firms' decisions to exit the market. Finally, Collard-Wexler (2013) studies the role of demand shocks in local markets for ready-mix concrete, finding a substantial market expansion effect.

\section{Data and Measurement}

\subsection{Ready-Mix Concrete}

I use US Census of Manufactures data for the ready-mix concrete industry (SIC 3273) from years 1982, 1987, and 1992. Ready-mix concrete is a mixture of cement, water, gravel, and chemical additives that is used in sidewalks, foundations, and roads, among other applications. These ingredients are combined at the plant and transported to the construction site in a large drum mounted on an even larger truck.

Two features make the industry particularly interesting for studying the role of market

\footnotetext{
${ }^{5}$ From footnote 6 of Syverson (2004a): "One can remain agnostic about the specific source of productivity gains when competition is intensified. One possibility is an effect on "slack" or X-efficiency. That is, competition-spurred productivity growth occurs because producers are forced to take costly action to become more efficient, as in Raith (2003), e.g. However, in the mechanism modeled here, productivity growth is instead achieved by selection across establishments with fixed productivity levels; less efficient producers are pushed out of the market. Both mechanisms are influenced by market competitiveness in theory, and both are likely to play a role in reality. Measuring the relative size of the contribution of each to determining productivity differences is beyond the scope of this paper, however."
} 
structure: first, there are markedly high transportation costs that make competition local in character. When the mixing truck is loaded the concrete begins to harden to the interior of the drum, wasting materials and incurring maintenance costs. Therefore construction sites are typically serviced by nearby plants. For my purpose, this motivates the definition of geographic market areas and affords cross-sectional variation in market structure.

The second important feature of the industry is the homogeneity of the output. Thought the composition of chemical additives may differ some by application, this generates little product differentiation. For this reason, in the years of my sample the Productivity Supplement to the Census of Manufactures collected output data in cubic yards, which obviates many of the concerns that would accompany the use of deflated revenue in estimating productivity for this application.

It is important to note that there is substantial entry and exit in this industry; in my sample roughly one third of plants disappear between each five-year census. Because the selection effect is predicated on differential exit, this tremendous amount of churn is favorable to the existence of such an effect. For a more extensive discussion of the ready-mix concrete industry, the interested reader is referred to Syverson (2008).

\subsection{Market Definition}

The empirical work that follows is identified off of cross-sectional variation in market competitiveness. This is motivated by the local character of competition, and therefore necessitates careful market definition. I follow Syverson (2004a) in using the 1995 Component Economic Areas (CEAs), which are constructed by the Bureau of Economic Analysis.

CEAs are a complete partition of the set of 3141 US counties into 348 market areas. They are constructed by assigning contiguous counties to nodes of economic activity (e.g. metro- or micropolitan areas). Assignment is based primarily on labor force commuting patterns from decennial census, and secondarily — for roughly $25 \%$ of non-nodal counties — by newspaper circulation data from the Audit Bureau of Circulations. See Johnson (1995) for more details on the construction of the 1995 CEA definitions.

Strictly speaking, the ideal market definition would be such that first, consumers in market A are never served by a firm in some other market B and second, all firms in each market have some strategic interaction. The use of CEAs is of course a compromise towards that 
Figure 1: Map of CEAs

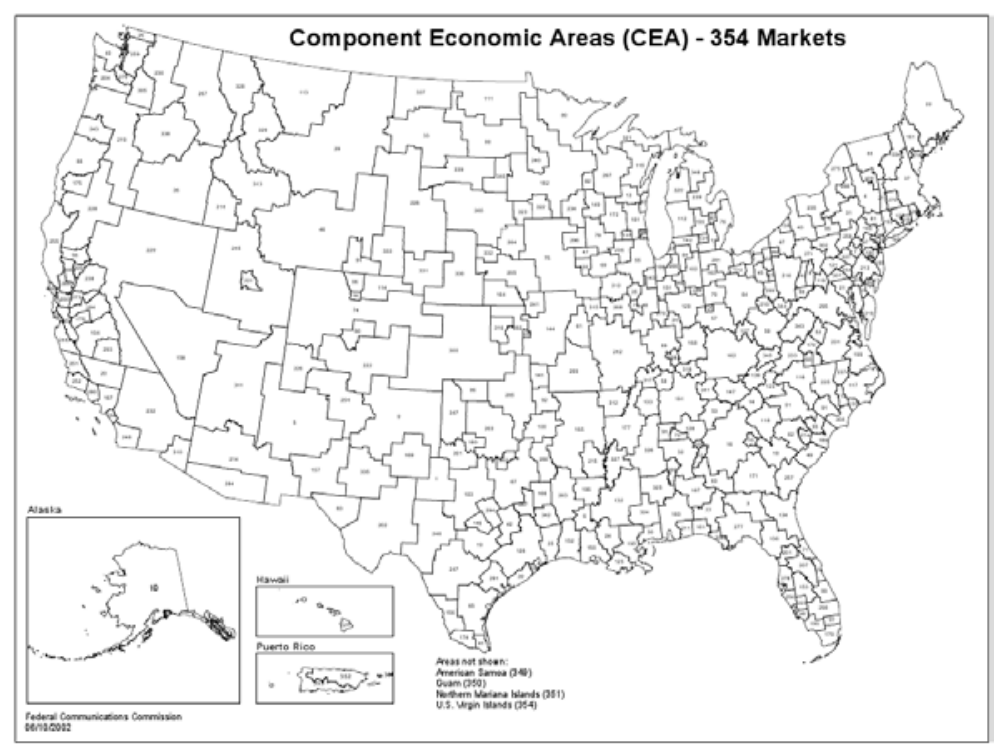

Notes: This figure depicts Component Economic Areas (CEAs) as constructed by the Bureau of Economic Analysis, a complete partition of the counties of the US into market areas. See Johnson (1995) for details on construction.

end. While labor force commuting patterns are likely a good proxy for market areas when population is dense, a key weakness of this market definition it that rural market areas tend to be overly large; see Figure 1. For this reason I exclude from my sample all plants in the top decile of the CEA geographic size distribution ${ }^{6}$

\subsection{Competition and Demand}

In order to exploit cross-sectional variation in competitiveness I require a competition index informed by the institutional features of the industry. I employ several variations on a count measure. My baseline and preferred specification is the number of ready-mix concrete establishments per square mile. This can be derived from a formal model of travel costs and geographic differentiation as in Syverson (2004a), but the intuition is simple and depends on a critical feature of the industry: that RMC plants are only differentiated geographically, by the transit costs of serving a customer. Therefore as demand grows, there are returns to opening new plants rather than merely expanding capacity. Then, as demand grows and more firms enter a finite geographic area, the geographic density of establishments increases and they are correspondingly less differentiated. In that sense establishments become more

\footnotetext{
${ }^{6}$ See Appendix A.2 for a complete discussion of my sample definition.
} 
substitutable and face greater competition.

The use of competition indices as a right-hand side variable in empirical work can be problematic. The difficultly is aptly summarized by Nickell (1996) in the context of a similar exercise: when firms are heterogeneous, single-dimensional indices will seriously mis-measure competitiveness. For instance, in the case of a count measure, a market may have few firms because barriers to entry stifle competition; alternatively, it may have few firms because it is competitive and the existing firms are very efficient 7 This particular example is problematic for my application, as it suggests that the measurement error of the competition index is correlated with establishment productivity, my left-hand side-variable, a point raised by Holmes and Schmitz (2010) - i.e., the measurement error is non-classical.

To overcome this, I use demand shifters to isolate variation in long-run competitive structure 8 If establishment level heterogeneity is transient, a point on which the literature is in consensus (Baily et al., 1992; Foster et al., 2008), then we can integrate out over these short-run shocks by using an instrument for the long-run expected competitive structure. Isolating this source of variation rationalizes the use of a single-dimensional competition index; in particular, I use the expected number of firms conditional on exogenous demand $!^{9}$ I introduce the following set of demand shifters as instruments for market size in ready-mix concrete: building permits issued, single-family building permits issued, and local government road and highway expenditures 40 These series are generated at the county level by

\footnotetext{
${ }^{7}$ Special thanks to James Schmitz for a colorful and helpful discussion on this point.

${ }^{8}$ By "long-run" here I mean the steady-state expectation with endogenous entry and exit.

${ }^{9}$ This appeal to long-run market fundamentals in order to understand the effect of market structure is not novel, and has been explored extensively in Sutton (1991). Falling barriers to trade and integration as European Community initiatives were rolled out created opportunities to study market expansion in Bottasso and Sembenelli (2001). Syverson (2004a) regresses market-level productivity dispersion on construction employment, which proxies for demand. The market expansion effect of demand shifters for ready-mix concrete is studied more closely by Collard-Wexler (2013), which shows that entry responds to changes in construction employment. Beyond ready-mix concrete, trade economists have exploited changes in entry costs for international firms or trade barriers in order to capture changes in the competitive environment, and Kneller and McGowan (2014) study the relationship between demand for ethanol on productivity in the corn sector.

${ }^{10}$ The reason I diverge from prior work and eschew county-level construction employment as a demand shifter for RMC is that I found that it consistently failed over-identification tests for exogeneity in my IV regressions. In some sense this might not be surprising because the measure of competition is so coarseit may be that it is affecting the outcome variable through competition in a way that my measure does not capture. Alternatively, and more worryingly, it is likely that county-level construction employment is correlated with measurement error in productivity inputs due to local wage effects. By excluding it I find that my model passes over-identification tests easily; see the over-identification test results (Hansen J) from Table 2. In the discussion of robustness in Section 6.2 I consider IV regressions with additional controls, including county construction employment.
} 
Table 1: Summary Statistics

\begin{tabular}{lcccccc}
\hline & \multicolumn{2}{c}{1982} & \multicolumn{2}{c}{1987} & \multicolumn{2}{c}{1992} \\
& mean & s.d. & mean & s.d. & mean & s.d. \\
\hline No. Estab. & 13.59 & 12.53 & 13.76 & 14.14 & 13.52 & 13.92 \\
log density & -6.02 & 0.85 & -6.04 & 0.86 & -6.04 & 0.86 \\
No. Firms & 9.51 & 7.45 & 10.46 & 9.11 & 10.43 & 9.23 \\
log density & -6.23 & 0.83 & -6.28 & 0.84 & -6.35 & 0.85 \\
HHI No. Estab. & 6.84 & 5.28 & 6.99 & 6.48 & 7.03 & 6.40 \\
log density & -6.61 & 0.88 & -6.63 & 0.90 & -6.61 & 0.90 \\
HHI No. Firms & 4.92 & 3.05 & 5.50 & 3.55 & 5.26 & 3.69 \\
log density & -6.86 & 0.85 & -6.92 & 0.85 & -6.95 & 0.88 \\
Building Permits & 2645.51 & 5629.57 & 4291.51 & 7642.50 & 2951.70 & 4165.11 \\
log density & -1.25 & 1.23 & -0.89 & 1.62 & -0.96 & 1.33 \\
S.F. Building Permits & 1419.62 & 2662.46 & 2851.15 & 4699.00 & 2443.78 & 3587.64 \\
log density & -1.84 & 1.28 & -1.22 & 1.55 & -1.17 & 1.33 \\
Road \& Hwy $\$$ & 38994.95 & 59188.68 & 56030.91 & 93206.21 & 72173.89 & 121158.15 \\
log density & 1.72 & 1.07 & 2.05 & 1.09 & 2.30 & 1.11 \\
\hline
\end{tabular}

Notes: This table contains summary statistics for measures of competition $c_{m(i) t}$ as well as demand shifters for ready-mix concrete. All variables are aggregated to the year-CEA level. For each variable I also report the log of the ratio of the variable to the area (in square miles) of the CEA, which is the form in which they enter the analysis that follows.

the US Census 11

A weakness of the count measure as a competition index is that it ignores observed concentration, which may be informative if there are dimensions other than productivity on which firms are heterogeneous (e.g., their ability to secure contracts, c.f. Foster et al. (2008)). For this reason I use the number equivalent of the Herfindal-Hirschman Index (HHI), i.e. HHI ${ }^{-1}$ as an alternative measure. Originally proposed by Adelman (1969), it can be interpreted as the number of symmetric firms that would generate the observed degree of concentration. As I will show in section 4.1, in some of my markets there are multiple establishments owned by the same firm. Without strong assumptions it is unclear whether the establishment count or the firm count is the better measure; therefore, in all of my results I present both.

Summary statistics for my competition variables as well as my market size instruments are presented in Table 1. They are described both in raw form as well as the log density form in which they enter the regressions below. For my preferred specification, the count of establishments, we see that a standard deviation increase implies an approximately eightyfive percent increase in the number of RMC plants per square mile.

\footnotetext{
${ }^{11}$ Historical series for these variables are available from USA counties database online, however this resource is no longer updated.
} 


\subsection{Productivity}

In all of my empirical analysis I treat establishment-level productivity residuals $\omega_{i t}$ as data. These productivity residuals are the additive error in a log Cobb-Douglas production function with constant returns to scale:

$$
q_{i t}=\alpha_{L t} l_{i t}+\alpha_{K^{E} t} k_{i t}^{E}+\alpha_{K^{S} t} k_{i t}^{S}+\alpha_{M t} m_{i t}+\alpha_{E t} e_{i t}+\omega_{i t}
$$

- where $q_{i t}$ is $\log$ physical output; $l_{i t}$ is labor, $k_{i t}^{E}$ and $k_{i t}^{S}$ are equipment and structural capital, respectively; $m_{i t}$ is expenditure on materials; $e_{i t}$ is energy expenditures, and the coefficients $\alpha$ are input elasticities, with $\sum_{k} \alpha_{k t}=1 .{ }^{12}$ The input elasticities $\alpha_{t}$ are consistently measured by input shares under the assumption that all but one inputs are flexible and that purchasers do not have market power. Here I allow that structural capital is inflexible and follow De Loecker and Warzynski (2012) and Asker et al. (2014) in exploiting the constant returns to scale assumption to identify $\alpha_{K^{S} t}=1-\alpha_{L t}-\alpha_{K^{E} t}-\alpha_{M t}-\alpha_{E t}{ }_{13}^{13}$ This requires that equipment capital is flexible, which is a reasonable assumption for ready-mix concrete this is largely made of up tools and ready-mix-concrete trucks, and the interested reader will find a healthy secondary market for the latter on eBay.com.

Estimation of the year-specific industry-wide input cost shares, which are taken as estimates of the input elasticities, follows the approach of Foster et al. (2008), detailed in Appendix A.114

As in prior work, my estimates of plant-level productivity exhibit a high degree of variance as well as intertemporal persistence. The standard deviation is 0.27 and the implied oneyear autocorrelation of $\omega_{i t}$ is 0.77 . See Appendix A.2 for details on the components and measurement of $x_{i t}$.

\footnotetext{
${ }^{12}$ The constant returns to scale assumption is critical because increasing returns to scale would generate a direct causal relationship between scale and (mis)measured productivity; I offer supplementary evidence for it as a robustness check in Section 6.1.

${ }^{13}$ Thanks to anonymous referee for suggesting this argument.

${ }^{14}$ Thanks to Chad Syverson for sharing these estimates.
} 


\section{Competition and Productivity}

In this section I present my reduced-form evidence on the correlation between competition and productivity as well as a decomposition analysis that sheds some light on the response of reallocation to greater competition.

\subsection{Reduced-Form Analysis}

I begin by estimating the following reduced-form relationship, which captures the correlation between competition and productivity:

$$
\omega_{i t}=\beta_{t}+\beta c_{m(i) t}+\varepsilon_{i t}
$$

- $\omega_{i t}$ is plant-level productivity, as defined in Section 3.4. and $c_{m(i) t}$ is a measure of competitiveness, as defined in Section 3.3. There is an important source of bias in the OLS variant of this model: the presence of high-productivity establishments may deter entry by competitors, which would motivate a negative correlation. One can think of this as a source of non-classical measurement error; conditional on realizations of establishment-level productivity, the number of firms may be a bad proxy for the degree of competition, and the error is correlated with plant-level productivity.

In order to obtain an unbiased estimate I use exogenous demand shifters to instrument for long-run market structure. Intuitively, I am integrating out over transient, short-run productivity shocks to obtain the unconditional effect of the number of firms on expected establishment-level productivity. Pursuant to the discussion in Section 3.3, I use the geographic density of building permits, single-family residential building permits, and local government road and highway expenditures. These demand shifters are relevant insofar as demand has a market expansion effect in equilibrium, consistent with standard industry dynamics models and the findings of Collard-Wexler (2013) for ready-mix concrete in particular. To make the argument for exogeneity I observe that ready-mix concrete is but a small part of most construction budgets; price changes due to changes in market power are unlikely to drive reverse causality in my application. However, a reasonable concern is that these shifters may have a direct effect on productivity, if for no other reason than measurement error in the competition index. For this reason I also present results from over-identification 
tests (Hansen J).

Results for OLS and IV estimation of (2) are presented in Table 2. The coefficient on competition is stable across models (1)-(4) and (5)-(8), suggesting little dependence on the particular choice of competitive index. Based on specification (5), a one standard deviation increase in the number of establishments per square mile (approximately 0.85, from Table 1), would predict a $3.98 \%$ increase in TFPQ. The most noticeable difference is across the OLS and IV specifications; as Nickell (1996) suggests, the bias introduced by correlation between productivity types and the measurement error in the competition index seems to be negative. Note as well that results from the over-identification tests consistently and safely fail to reject the hypothesis of exogeneity of the instruments. If demand had a an indirect causal effect, whether due to mis-measurement of the competition index or some other hypothesis, e.g. agglomeration effects of market size, I should reject this hypothesis. The results support the choice of measure of competition, and also helps to rule out alternative channels by which demand might affect productivity.

These results imply that there is an economically and statistically significant relationship between competition and productivity, and that relationship is causal. What they do not shed light on, however, is whether that causal effect is driven by the treatment effect of competition or the selection effect. The former effect is a within-establishment causal effect of competition - it behaves as if competition were an input to production. The latter is driven entirely by selective attrition of low-productivity establishments in more competitive markets. Separating these two stories is the objective of Sections 5.1 and 5.2 .

\subsection{Decomposition Approach}

There is substantial variation in plant size, and so it is natural to wonder whether the average effects reported in Table 2 would be diminished if we weighted plants according to their output. And if we found such a difference, we should ask whether there is greater reallocation of demand to more productive plants in more competitive markets. To structure this exercise, I borrow a static decomposition of productivity from Olley and Pakes (1996), write output-weighted average productivity, denoted $p_{m t}$, in terms of an unweighted mean and a covariance term: 


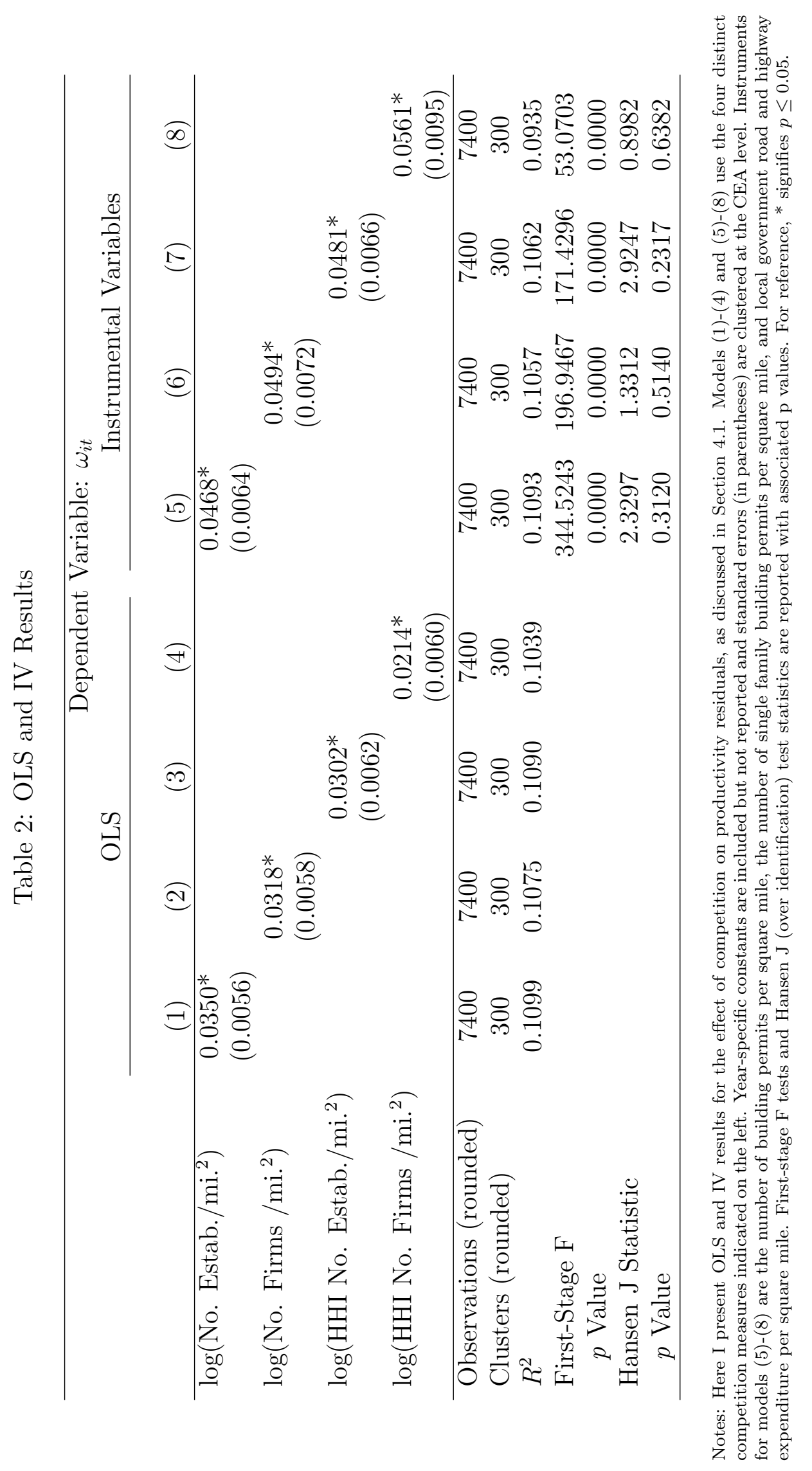


Table 3: Decomposition Results

\begin{tabular}{lcccc}
\hline & & 1982 & 1987 & 1992 \\
\hline Output-weighted Productivity $\left(p_{m t}\right)$ & mean & 1.00 & 1.13 & 1.19 \\
& s.d. & 0.17 & 0.19 & 0.17 \\
Unweighted Average Productivity $\left(\bar{\omega}_{m t}\right)$ & mean & 0.97 & 1.11 & 1.17 \\
& s.d. & 0.16 & 0.15 & 0.17 \\
Productivity-Output Covariance $\left(\Gamma_{m t}\right)$ & mean & 0.03 & 0.02 & 0.03 \\
& s.d. & 0.08 & 0.10 & 0.07 \\
\hline
\end{tabular}

Notes: This table contains decomposition results for the OP static decomposition at the CEA-Year level. See equation (3) for construction of terms of the decomposition.

$$
\begin{aligned}
& p_{m t} \equiv \sum_{\{i: m(i)=m\}} s_{i t} \omega_{i t} \\
& =\sum_{\{i: m(i)=m\}} \bar{s}_{m t} \bar{\omega}_{m t} \\
& +\underbrace{\bar{s}_{m t} \sum_{\{i: m(i)=m\}}\left(\omega_{i t}-\bar{\omega}_{m t}\right)}_{=0}+\underbrace{\bar{\omega}_{m t} \sum_{\{i: m(i)=m\}}\left(s_{i t}-\bar{s}_{m t}\right)}_{=0} \\
& +\sum_{\{i: m(i)=m\}}\left(s_{i t}-\bar{s}_{m t}\right)\left(\omega_{i t}-\bar{\omega}_{m t}\right) \\
& =\bar{\omega}_{m t}+\underbrace{\sum_{\{i: m(i)=m\}}\left(s_{i t}-\bar{s}_{m t}\right)\left(\omega_{i t}-\bar{\omega}_{m t}\right)}_{\equiv \Gamma_{m t}} .
\end{aligned}
$$

The term $\bar{\omega}_{m t}$, which appears on the last line, is unweighted average productivity. The second term in the final line, $\Gamma_{m t}$, is the covariance of establishment-level productivity and market share. This, in the literature on productivity, is taken as a direct measure of reallocation. I compute these terms at the CEA level for my dataset, and results are presented in Table 3. Two features stand out - first, note that there is substantial variation in $\bar{\omega}_{i t}$ at the year-CEA level. This will be very important for motivating the grouped quantile IV approach that I adopt in Section 5.2 below. Second, there is substantial productivity growth in the period which seems to be mostly driven by unweighted average productivity changes. I observe little change in $\Gamma_{m t}$ on average, but note that there is substantial variation across markets 
which may be correlated with competition 15

Typically, by the time we aggregate to the year-market level as the decomposition requires, we have very little data ${ }^{16}$ Here, however, the local character of ready-mix concrete markets allows us a chance to put these decomposition terms in a regression framework. This means that we can do statistical rather than eyeball inference. I run the following simple regression:

$$
y_{m t}=\beta_{t}+\beta c_{m t}+\varepsilon_{m t}
$$

- which differs from equation 2 in two ways: first, the unit of observation is the market rather than the plant, and second, the left-hand side variable is $y_{m t} \in\left\{p_{m t}, \bar{\omega}_{m t}, \Gamma_{m t}\right\}$. As before, I include year fixed effects and standard errors are clustered at the CEA level. Results for variants of these regressions are presented in Table 4.

Reassuringly, the coefficients in models (5)-(8) are close to those we found in the IV results of Table 2. Also, mechanically, the coefficients in, e.g., models (5) and (9) add up to the coefficient in model (1). Therefore the striking similarity of the coefficients in models (1)-(4) and (5)-(8) implies that the coefficients in (9)-(12) must be very close to zero, and they are. This is the most striking feature of these results — that there is no statistically significant correlation between competition and $\Gamma_{m t}$. Even as ready-mix plants become more densely situated and therefore more substitutable, we are not able to detect a reallocation of demand to more productive plants. According to Foster et al. (2001), changes in $\Gamma$ made up about a third of average industry change in multifactor productivity between 1977 and 1987. At least in ready-mix concrete, this does not appear to be a response to changes in the competitive environment.

\footnotetext{
${ }^{15}$ Many papers in the productivity literature follow Baily et al. (1992) in decomposing productivity changes into four parts: changes among surviving firms, reallocation among surviving firms, exiting firms, and entrants. Collard-Wexler and De Loecker (2015) adopt this approach (but note the problems below), and Melitz and Polanec (2013) use it to develop a dynamic version of the OP decomposition. Unfortunately (and somewhat surprisingly), distinguishing between surviving, exiting, and entrant firms may confuse rather than clarify the treatment versus selection effect question. The treatment effect is not confined to surviving firms; instead, it will affect exiting end entrant firms as well - differentially insofar as it affects the exit threshold. Similarly, the selection effect is not confined to exiting firms; it will also bias the sample of surviving firms in favor of those that have positive productivity changes, as those with negative productivity changes are more likely to cross the (higher) exit threshold. What is unique to the selection effect hypothesis is reallocation, which is most clearly captured by the covariance term of the OP decomposition I use here.

${ }^{16}$ As in, e.g., Olley and Pakes (1996), where an increase in $\Gamma_{t}$ following the divestiture of AT\&T is the best evidence we have that reallocation was an important mechanism for produvtivity gains.
} 
Table 4: Decomposition Regression Results

\begin{tabular}{|c|c|c|c|c|}
\hline & \multicolumn{4}{|c|}{ Dependent Variable: $\tilde{\omega}_{t}$} \\
\hline & (1) & $(2)$ & (3) & (4) \\
\hline $\log \left(\right.$ No. Estab. $\left./ \mathrm{mi}^{2}{ }^{2}\right)$ & $\begin{array}{l}0.0463^{*} \\
(0.0086)\end{array}$ & & & \\
\hline $\log \left(\right.$ No. Firms/mi. $\left.{ }^{2}\right)$ & & $\begin{array}{l}0.0482^{*} \\
(0.0092)\end{array}$ & & \\
\hline $\log \left(\right.$ HHI No. Estab. $\left./ \mathrm{mi}^{2}{ }^{2}\right)$ & & & $\begin{array}{l}0.0459^{*} \\
(0.0087)\end{array}$ & \\
\hline $\log \left(\right.$ HHI No. Firms $\left./ \mathrm{mi}^{2}{ }^{2}\right)$ & & & & $\begin{array}{l}0.0513^{*} \\
(0.0103)\end{array}$ \\
\hline Observations (rounded) & 800 & 800 & 800 & 800 \\
\hline Clusters (rounded) & 300 & 300 & 300 & 300 \\
\hline$R^{2}$ & 0.2026 & 0.2012 & 0.1931 & 0.1783 \\
\hline & $(5)$ & $\begin{array}{l}\text { ependent } \\
\text { (6) }\end{array}$ & $\begin{array}{l}\text { Variable: } \\
\quad(7)\end{array}$ & (8) \\
\hline $\log \left(\right.$ No. Estab./mi. ${ }^{2}$ ) & $\begin{array}{l}0.0434^{*} \\
(0.0078)\end{array}$ & & & \\
\hline $\log \left(\right.$ No. Firms/mi. $\left.{ }^{2}\right)$ & & $\begin{array}{l}0.0455^{*} \\
(0.0083)\end{array}$ & & \\
\hline $\log \left(\right.$ HHI No. Estab. $\left./ \mathrm{mi}^{2}{ }^{2}\right)$ & & & $\begin{array}{l}0.0426^{*} \\
(0.0079)\end{array}$ & \\
\hline $\log \left(\right.$ HHI No. Firms $/$ mi. $\left.^{2}\right)$ & & & & $\begin{array}{l}0.0483^{*} \\
(0.0093)\end{array}$ \\
\hline Observations (rounded) & 800 & 800 & 800 & 800 \\
\hline Clusters (rounded) & 300 & 300 & 300 & 300 \\
\hline$R^{2}$ & 0.2467 & 0.2456 & 0.2415 & 0.2261 \\
\hline & (9) & $\begin{array}{l}\text { pendent } \\
\text { (10) }\end{array}$ & $\begin{array}{c}\text { Variable: } \\
(11)\end{array}$ & (12) \\
\hline $\log \left(\right.$ No. Estab./mi. $\left.{ }^{2}\right)$ & $\begin{array}{c}0.0029 \\
(0.0036)\end{array}$ & & & \\
\hline $\log \left(\right.$ No. Firms $/$ mi. $\left.^{2}\right)$ & & $\begin{array}{c}0.0026 \\
(0.0037)\end{array}$ & & \\
\hline $\log \left(\right.$ HHI No. Estab./mi. $\left.{ }^{2}\right)$ & & & $\begin{array}{c}0.0034 \\
(0.0036)\end{array}$ & \\
\hline $\log \left(\right.$ HHI No. Firms $\left./ \mathrm{mi}^{2}{ }^{2}\right)$ & & & & $\begin{array}{c}0.0030 \\
(0.0041)\end{array}$ \\
\hline Observations (rounded) & 800 & 800 & 800 & 800 \\
\hline Clusters (rounded) & 300 & 300 & 300 & 300 \\
\hline$R^{2}$ & 0.0018 & 0.0016 & 0.0001 & 0.0000 \\
\hline
\end{tabular}

Notes: This table presents IV results for the effect of competition on components of the OP weighted average productivity decomposition. Models (1)-(4) use $p_{m t}$, weighted average productivity at the CEA-year level; (5)-(8) use unweighted average productivity at the CEA-year level, and (9)-(12) use the covariance of market share and productivity at the CEA-year level. Year-specific constants are included but not reported and standard errors (in parentheses) are clustered at the CEA level. Instruments include the number of building permits per square mile, the number of single family building permits per square mile, and local government road and highway expenditure per square mile. For reference, ${ }^{*}$ signifies $p \leq 0.05$. 
Already, this result bodes poorly for the selection hypothesis. Models that generate selection effects of competition hinge on an assumption that as a market becomes more competitive, demand is reallocated to more productive plants. If that assumption fails, then we may see no effect or even the opposite correlation. See Appendix B for a formal discussion on this point. However, this is an incomplete argument against selection: first, while $\Gamma_{m t}$ has been advanced by empiricists as an intuitive counterpart of the reallocation mechanism, it is not the direct empirical counterpart of the underlying assumption. Second, if the selection effect is operative, then it will positively bias the estimate of models (1)-(4) and (5)-(8). For intuition, it is helpful to think of the effect of competition on $\Gamma_{m t}$, see models (9)-(12), as a measure of the average infra-marginal effect of reallocation, where the selection effect is the extensive margin, driving firm exit. But without restrictive assumptions about how reallocation affects firms with different levels of productivity, measuring one does not offer us direct access to the other.

\section{Treatment and Selection Effects of Competition}

In this section I offer two perspectives on the conflation of the treatment and selection effects in the IV results of Table 2, one model-dependent, which allows me to quantitatively decompose treatment and selection, and one less so, which allows me to test the claim that the selection effect primarily generates the correlation.

\subsection{Semi-parametric Disambiguation}

The first identification strategy I propose is based on an explicit model of the firm's exit choice, the problem driving the selection effect hypothesis. By modeling this I can construct a semi-parametric selection correction, i.e. a control function, that will allow me to decompose the causal effect identified in the IV approach of Section 4.1 into a treatment component and a selection component. Then I quantify and compare their relative contributions. 


\subsubsection{Behavioral Model}

Consider a firm's exit decision in a model of Markov industry dynamics cast after Ericson and Pakes (1995). There is a finite set of active firms in a market. $\mathcal{S}_{t}$ denotes the state of the market in period $t$, which has three components: a vector of idiosyncratic productivity types for each active firm, $\Phi_{t}$; a set of states, $X_{t}$, determined by firms' dynamic choices, and a market-level demand shifter, $d_{t}$. The game is public, so the information set of each establishment at time $t$ corresponds to the entire history of $\mathcal{S}_{t}$. In a Markov perfect equilibrium, firms make choices that depend only on $\mathcal{S}_{t}$, and in turn their actions determine Markov transition probabilities for the entire state of the game.

Establishments enter, exit, and make choices to maximize the expected discounted value of their profits. Stage game profits for establishment $i$ are written $\pi_{i}\left(\mathcal{S}_{t}\right)$. This function abstracts from stage-game decisions without dynamic effects, e.g. choice of price or quantity. Establishments also make dynamic choices, denoted by $a_{t}$, to affect the evolution of $X_{t}$, at a cost $c_{i}\left(a_{i}, \mathcal{S}_{t}\right)$. All active establishments also make an exit decision, and potential establishments make an entry decision.

The order of play determines the informational content of firms' decisions, and is therefore central to identification, a feature which is signature to the semi-parametric production function estimation literature. I assume a three-part period structure; this is my first identifying assumption:

Assumption 1. (timing of play)

$$
\Phi_{t} \text { evolves } \rightarrow \text { stage game } \pi \quad \rightarrow \quad \text { entry, exit, } a_{t} \text { chosen }
$$

At the beginning of the period, $\Phi_{t}$ is announced. Next, establishments produce and realize stage game profits according to $\pi$. Third and finally, potential entrants arrive and all establishments make exit and choose actions $a_{t}$ (e.g., investment). Establishments only make choices in the third and final stage. What is significant about the timing structure is that the stage game precedes exit; for intuition, the model is consistent with the notion that firms learn their new productivity draw by producing. The Bellman function of the active establishment, which chooses whether to exit and obtain a scrap value normalized to zero and, should they choose to persist, actions $a_{i t}$ subject to costs $c\left(a_{i t}, X_{t}\right)$ can be written: 


$$
V_{i}\left(\mathcal{S}_{t}\right)=\max \left\{0, \max _{a_{i t}}\left\{\delta \mathbb{E}\left[\pi_{i}\left(\mathcal{S}_{t+1}\right)+V_{i}\left(\mathcal{S}_{t+1}\right) \mid a_{t}\right]-c_{i}\left(a_{i t}, \mathcal{S}_{t}\right)\right\}\right\}
$$

This Bellman equation nests two decisions, but the one I am interested in is the exit choice. Conditioning on equilibrium play by other agents, let $v_{i}\left(\mathcal{S}_{t}\right)$ denote the solution to the inner maximization problem. Now the establishment's optimal exit choice can be characterized by:

$$
\chi_{i}\left(\mathcal{S}_{t}\right)= \begin{cases}1 & \text { if } v_{i}\left(\mathcal{S}_{t}\right) \geq 0 \\ 0 & \text { else. }\end{cases}
$$

Moreover, in general it is possible to show that this exit choice can, in equilibrium, be written as a threshold rule ${ }^{17}$ That is, there exists some $\phi_{i}^{*}\left(\mathcal{S}_{t}\right)$ such that the establishment chooses to exit if $\phi_{i t}<\phi_{i}^{*}\left(\mathcal{S}_{t}\right)$. This exit threshold drives the selection effect hypothesis, per the discussion in Section 2.2.

My second identifying assumption is the exogeneity of innovations in firms' productivity types, $\phi_{i t}$ :

Assumption 2. (exogeneity of innovations)

$$
p\left(\phi_{i t+1} \mid \mathcal{S}_{t}\right)=p\left(\phi_{i t+1} \mid \phi_{i t}\right)
$$

See Ackerberg et al. (2015) for a fuller discussion of this assumption; as an economic assumption it implies that establishments do not make choices that affect the evolution of their idiosyncratic productivity type $\phi$. Econometrically, the assumption is useful because it affords me a source of exogenous variation in the model.

\subsubsection{Identification}

As a straw man, consider the naïve structural interpretation of the linear model I estimated in Section 4.1;

\footnotetext{
${ }^{17}$ See Doraszelski and Satterthwaite (2010) for a discussion of the purification arguments required to guarantee existence of a threshold/cutoff strategy in Markov games based on Ericson and Pakes (1995).
} 


$$
\omega_{i t}=\beta_{t}+\beta_{c} c_{m(i) t}+\phi_{i t} .
$$

All that has changed from the earlier reduced-form model in (2) is notation and interpretation: the error term $\varepsilon_{i t}$ has become $\phi_{i t}$, the primitive, underlying productivity type of the plant, and $\beta$ has become $\beta_{c}$, a treatment effect of competition on productivity. Viewed this way it is easy to see why the instrumental variables approach does not identify $\beta_{c}$. The sample is selected: according to my behavioral model I only observe plants that survived the prior period, i.e. such that $\phi_{i t-1} \geq \phi_{i}^{*}\left(\mathcal{S}_{t}\right)$. Therefore $c_{m(i) t}$ and $\phi_{i t}$ will be correlated, which biases the estimate of $\beta_{c}$. That bias is the selection effect 18 My identification argument is shows that, subject to the assumptions of my model, the bias can be estimated, and $\beta_{c}$ recovered.

It begins by formalizing the bias term. First, take the expectation of both sides of equation (7) conditioning on the the state of the market at time $t-1$ and the survival of the establishment:

$$
\begin{aligned}
& \mathbb{E}\left[\omega_{i t} \mid \mathcal{S}_{t-1}, \phi_{i t-1} \geq \phi_{i}^{*}\left(\mathcal{S}_{t-1}\right)\right] \\
& \quad=\beta_{t}+\beta_{c} \mathbb{E}\left[c_{m(i) t} \mid \mathcal{S}_{t-1}, \phi_{i t-1} \geq \phi^{*}\left(\mathcal{S}_{t-1}\right)\right]+\mathbb{E}\left[\phi_{i t} \mid \mathcal{S}_{t-1}, \phi_{i t-1} \geq \phi_{i}^{*}\left(\mathcal{S}_{t-1}\right)\right] .
\end{aligned}
$$

Focusing on the last term,

$$
\begin{aligned}
\mathbb{E}\left[\phi_{i t} \mid \mathcal{S}_{i t-1}, \phi_{i t-1} \geq \phi_{i}^{*}\left(\mathcal{S}_{t-1}\right)\right] & =\mathbb{E}\left[\phi_{i t} \mid \mathcal{S}_{i t-1}\right] \\
& =\mathbb{E}\left[\phi_{i t} \mid \phi_{i t-1}\right] \\
& =g\left(\phi_{i t-1}\right) .
\end{aligned}
$$

The first equality follows from Assumption 1; the timing structure implies that the event $\phi_{i t-1} \geq \phi_{i}^{*}\left(\mathcal{S}_{t-1}\right)$ is fully determined by $\mathcal{S}_{t-1}$. The second equality follows directly from Assumption 2. Now define $\eta_{i t} \equiv \phi_{i t}-\mathbb{E}\left[\phi_{i t} \mid \phi_{i t-1}\right]$. From Assumption 2 we know that this innovation $\eta_{i t}$ is exogenous to all of the arguments in $\mathcal{S}_{t}$. Plugging this into (7) yields

\footnotetext{
${ }^{18}$ The IV estimate is still causal, despite the fact that it conflates the two possible channels (treatment and selection), however it is uninterpretable in terms of primitives.
} 


$$
\omega_{i t}=\beta_{t}+\beta_{c} c_{m(i) t}+g_{t}\left(\phi_{i t-1}\right)+\eta_{i t}
$$

- which can be evaluated by inverting the model in (7) and plugging it in for $\phi_{i t-1}$. This allows me to identify the treatment effect of competition on productivity, $\beta_{c}$. Note that the control function $g_{t}(\cdot)$ is an unknown and potentially complicated function implied by the model; absent further assumptions it will be important to estimate this function flexibly, which is the sense in which my approach is semi-parametric.

\subsubsection{Estimation}

I estimate the model using nonlinear GMM with two sets of moments. The first is derived from equation (10):

$$
\mathbb{E}\left[\eta_{i t} \mid Z_{i t}\right]=0
$$

In order to construct $\eta_{i t}$ I use a third-order polynomial series to approximate $g_{t}(\cdot)$. This is the source of the nonlinearity - the argument of the polynomial series is the lagged residual from (7), which depends on the parameters of interest. To control for measurement error I continue to use my exogenous demand shifters as instruments for $c_{m(i) t}$.

Moment (M1) is sufficient to estimate treatment effect of competition on productivity, but I would also like to be able to quantify the contribution of the selection effect. To see how I

do this, consider the following thought experiment: given an estimate $\hat{\beta}_{c}$, one could go back and construct an estimate of productivity net of the treatment effect of competition. Taking that estimate as a dependent variable, next run the following regression:

$$
\underbrace{\omega_{i t}-\hat{\beta}_{c} c_{m(i) t}}_{=\phi_{m(i) t}}=\alpha_{t}+\alpha_{c} c_{m(i) t}+u_{i t} .
$$

Since I have subtracted off the treatment effect $\hat{\beta}_{c} c_{m(i) t}$ from the left-hand side, what $\alpha_{c}$ is capturing is the selection bias induced by correlation between $c_{m(i) t}$ and $\phi_{i t}$. If there is no selection effect, then I expect to find $\hat{\alpha}_{c}=0$. Estimating this term allows me to quantify the 
Table 5: Semiparametric Results

\begin{tabular}{|c|c|c|c|c|}
\hline & \multicolumn{4}{|c|}{ Dependent Variable: $\omega_{i t}$} \\
\hline & $(1)$ & $(2)$ & $(3)$ & $(4)$ \\
\hline $\log \left(\right.$ No. Estab./mi. $\left.{ }^{2}\right)$ & $\begin{array}{l}0.0456^{*} \\
(0.0090)\end{array}$ & & & \\
\hline $\log \left(\right.$ No. Firms $/$ mi. $\left.^{2}\right)$ & & $\begin{array}{l}0.0488^{*} \\
(0.0118)\end{array}$ & & \\
\hline $\log \left(\right.$ HHI No. Estab. $\left./ \mathrm{mi}^{2}\right)$ & & & $\begin{array}{l}0.0503^{*} \\
(0.0101)\end{array}$ & \\
\hline $\log \left(\right.$ HHI No. Firms $\left./ \mathrm{mi}^{2}\right)$ & & & & $\begin{array}{c}0.0571^{*} \\
(0.0150)\end{array}$ \\
\hline Selection Coeff. $\left(\alpha_{c}\right)$ & $\begin{array}{c}0.0046 \\
(0.0030)\end{array}$ & $\begin{array}{c}0.0049 \\
(0.0065)\end{array}$ & $\begin{array}{c}0.0005 \\
(0.0041)\end{array}$ & $\begin{array}{c}0.0043 \\
(0.0085)\end{array}$ \\
\hline Observations (rounded) & 3100 & 3100 & 3100 & 3100 \\
\hline Clusters (rounded) & 300 & 300 & 300 & 300 \\
\hline
\end{tabular}

Notes: This table presents results for the semi-parametric selection correction procedure detailed in Section 5.1 using four different indices for competition. Year-specific constants are included but not reported and standard errors (in parentheses) are clustered at the CEA level. For reference, ${ }^{*}$ signifies $p \leq 0.05$.

relative contribution of the selection effect to the IV estimates obtained in Section $4.1^{19}$ This motivates the second set of moments I use in estimation, which implement the regression in equation (11):

$$
\mathbb{E}\left[u_{i t} \mid Z_{i t}\right]=0
$$

I estimate the model using moments (M1) and (M2). Results are presented in Table 5 . As a simple diagnostic check, since this is a decomposition of the causal effect of competition on productivity, the sum of $\beta_{c}$ and $\alpha_{c}$ should be roughly equal to my IV estimate from Table 2 for the corresponding competition index. None of my specifications reject this hypothesis ${ }^{20}$ With respect to the results themselves, the stark finding across all specifications is that the treatment effect seems to be driving almost all of the causal effect of competition on productivity. Where competition is measured by the number of RMC establishments per square mile, my estimates imply that doubling the number of establishments will raise output by $4.56 \%$ due to within-establishment responses to competition and $0.46 \%$ due to market

\footnotetext{
${ }^{19}$ Note, however, that $\alpha_{c}$ is not a primitive; it only measures the contribution of the selection effect in equilibrium.

${ }^{20}$ Note that the reason the correspondence is imprecise is because of the change of sample; the semiparametric selection correction approach uses only observations from 1987 and 1992.
} 
selection on productivity type. Importantly, for none of my specifications is the estimate of the selection effect bias statistically different from zero.

Summarizing, the effect of competition on productivity seems to be driven by a withinfirm response - a treatment effect - instead of market selection driven by reallocation of

demand - the selection effect. However, the argument here is subject to the very strong, if conventional, assumptions of the model: timing and exogeneity of productivity innovations. To strengthen this result in Section 5.2 below I adopt a less model-dependent approach to looking for evidence of a selection effect.

\subsection{Quantile Analysis}

Industry dynamics models, in particular those on which the selection effect hypothesis relies, make predictions not merely for the first moment of productivity or the second, but the shape of the entire distribution. In this section I use a grouped quantile IV regression to see whether the response of the empirical productivity distribution to competition is consistent with the selection effect hypothesis.

\subsubsection{Identification}

The identification strategy in this section hinges on the distinct predictions of the treatment effect and the selection effect for changes in the distribution of productivity types among active establishments in equilibrium as the market becomes more competitive. A visual motivation for the distinction is presented in Figure 2. The distribution of productivity types is assumed to be left-truncated, which reflects a threshold rule for exit common in industry dynamics models. Figure 2a depicts an additive shift in the entire distribution, consistent with the linear model described in (2). Alternatively, Figure 2b depicts a positive shift that is driven by an increase in the left-truncation point. The key difference here is that in the latter case, the increase in average productivity is driven entirely by an increase in the distribution at lower quantiles. Consistent with the selection effect, the higher end of the productivity distribution, which is determined by technological primitives, is invariant. In other words, the selection effect predicts that the marginal effect of competition should be declining in the quantile of the market-level productivity distribution. 
Figure 2: Treatment Effect vs. Selection Effect on Distribution of Productivity

(a) Treatment Effect

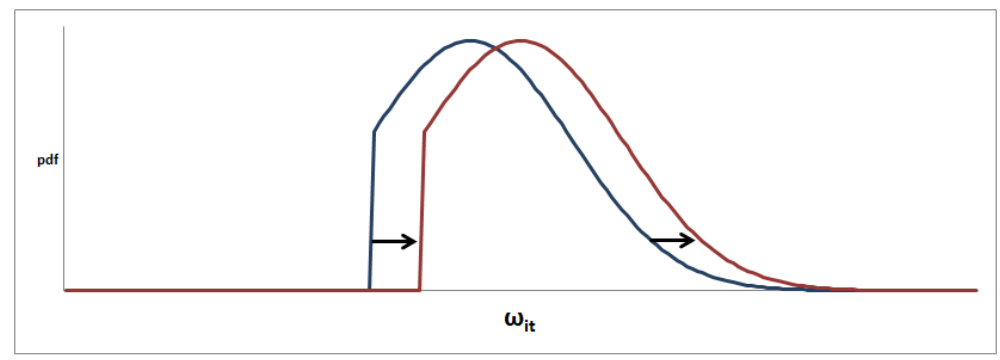

(b) Selection Effect

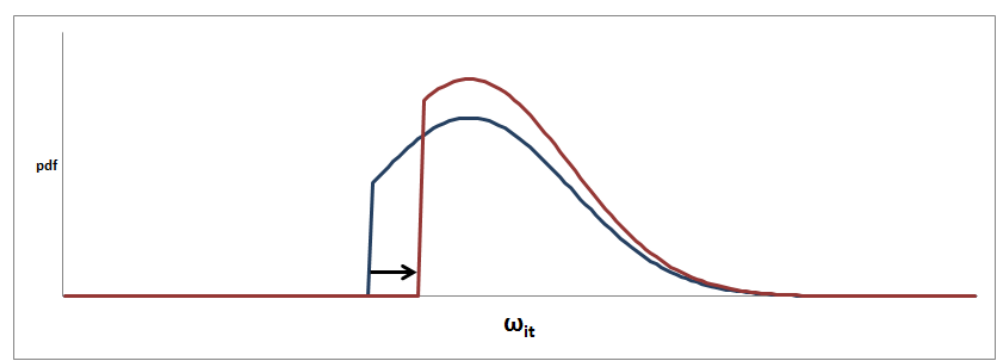

Notes: This figure illustrates two changes in the distribution of productivity residuals; in panel (a) a linear shift of the entire distribution, and in panel (b) a shift in the left truncation point. These correspond to the treatment effect and selection effect hypotheses, respectively.

It is important to note that the common shift depicted in Figure 2a, meant to represent the treatment effect hypothesis, is entirely driven by the parametric assumption of a common, constant treatment effect in model (2). Indeed, if the treatment effect is motivated by bankruptcy aversion then the lower tail of the distribution should be more responsive to competitive pressures. For this reason we cannot use this approach to credibly test whether the treatment effect is at play. However, the truncation interpretation of the selection effect does not depend on parametric form, and therefore we can test whether the effect of competition on productivity is monotonically declining to zero as we look at the effect on higher quantiles ${ }^{21}$ This test is less decisive than the semi-parametric approach in Section 5.1. but has the advantage that it requires correspondingly fewer assumptions and offers a simple visual interpretation.

\footnotetext{
${ }^{21}$ Note that this argument can be weakened substantially- in a more complex model the truncation point may depend on other attributes of the market or of the establishment. I handle market effects explicitly with my grouped quantile approach, which allows for market-specific random effects on productivity. Establishment-specific determinants of exit will make exit appear probabilistic given limited data, but none the less the left tail of the productivity distribution should exhibit more sensitivity.
} 
Figure 3: Effect of the (log) No. Establ. $/ \mathrm{mi}^{2}{ }^{2}$ on Productivity by Decile

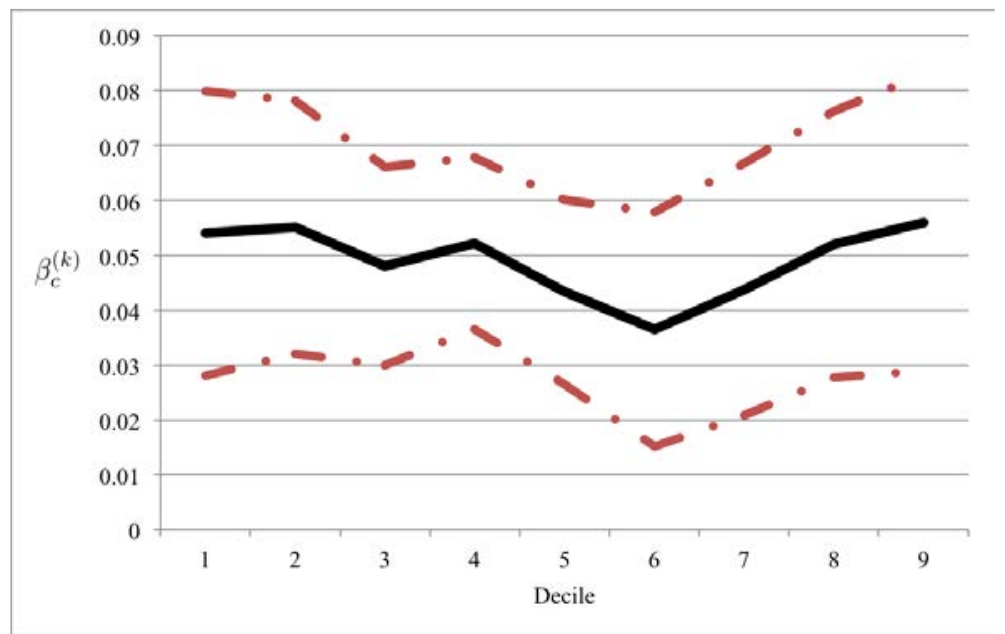

Notes: Here I present graphically the results from Table 6 for the case where the density of ready-mix establishments is taken as the competition index. Equivalent diagrams for alternative competition indices are qualitatively similar. The dashed line represents a $95 \%$ confidence interval.

\subsubsection{Estimation}

I begin by aggregating my data to the market level. Let $\rho_{m t}^{(k)}$ be the $k$ th decile of the marketlevel distribution of $\omega_{i t}$. Now I am interested in the following empirical model:

$$
\rho_{m t}^{(k)}=\beta_{t}^{(k)}+\beta_{c}^{(k)} c_{m t}+\nu_{m t}
$$

Aggregating to the market level is important here; this is the sense in which it is a "grouped quantile" approach. Alternatively, one could pool across markets and run a standard IV quantile regression. However, identification in that model depends on a rank similarity condition - that the error term is identically distributed across markets (Chernozhukov and Hansen, 2005). This is contradicted both by the theory motivating the selection effect hypothesis and also, more importantly, by the likely existence of other market-level factors affecting productivity. The advantage of the grouped quantile IV regression approach is that, by making the group quantile the dependent variable, it nets out the common, group-level effects.22

There is, however, a subtle source of bias in (12) as an empirical model: as we see from Table

\footnotetext{
${ }^{22}$ See Chetverikov et al. $(2013)$ for further discussion of the grouped IV quantile regression approach.
} 


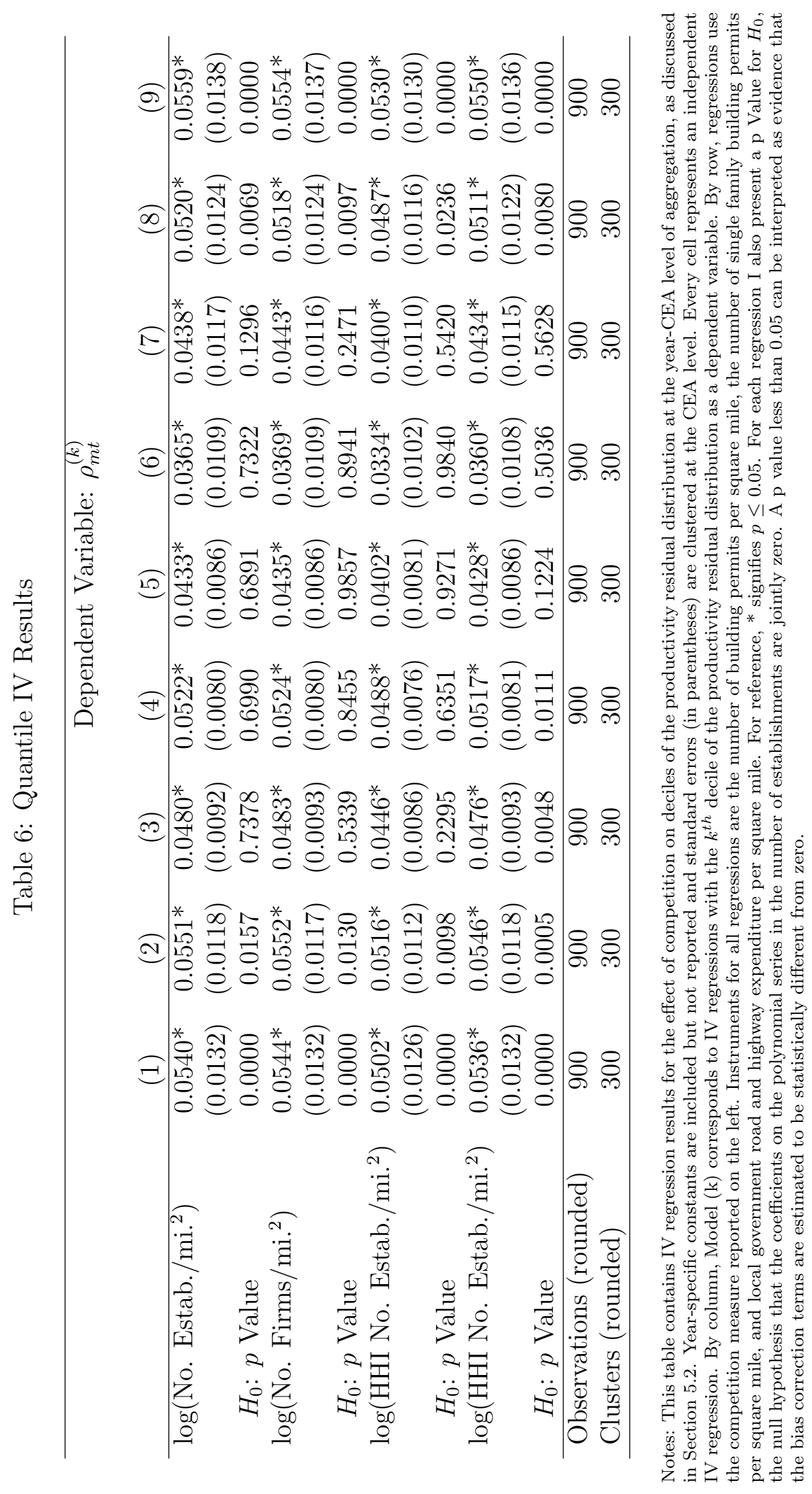


1, in many of my markets there are only a handful of establishments. This introduces an incidental parameters problem (Neyman and Scott, 1948). Fortunately, we can characterize the bias it introduces. If the number of establishments is small relative to the number of quantiles, then the higher (lower) quantiles will be equal to the highest (lowest) order statistic of the distribution. Those order statistics are mechanically correlated with the number of draws from which they are taken, and therefore mechanically correlated with count measures of competition. I call this "order statistic bias." In this application it implies that the $\hat{\beta}_{c}^{(k)}$ will be biased downward for small $k$ and upward for large $k$, where the productivity effect of competition is conflated with the mechanical properties of order statistics. To control for this effect I instead estimate the following regression:

$$
\rho_{m t}^{(k)}=\beta_{t}^{(k)}+\beta_{c}^{(k)} c_{m t}+g^{(k)}\left(n_{m t}\right)+\nu_{m t}
$$

- where $n_{m t}$ is the number of establishment observations which are aggregated up to the market level for this regression, and $g^{(k)}(\cdot)$ is an unknown function which I approximate with a third-order polynomial series, independently for each $k$. This term functions as a semi-parametric correction for the order statistic bias described above, and implies that we are identifying $\beta_{c}^{(k)}$ of of changes in competitive density alone. In Appendix Section app:montecarlo I offer a simple Monte Carlo exercise that replicates the basic features of this exercise and shows first, that the bias is present, and second, how the bias correction restores the desired coverage of the grouped quantile IV estimator.

Recall from section 5.2 .1 the prediction of the selection effect hypothesis: $\beta_{c}^{(k)}$ should be positive and declining to zero as $k$ goes from 1 to 9 . As before, I instrument for $c_{m t}$ using my market level demand shifters: the geographic density of building permits, single-family building permits, and local government road and highway expenditures.

Results for the four models — each using a distinct competition measure - for deciles $k=1, \ldots, 9$ are presented in Table 6 and visually in Figure 3 . There is some evidence of a declining effect in the left tail, consistent with the selection effect. However the stark and surprising result, for each of these models, is that the highest productivity establishments seem to enjoy not only a nonzero effect, but a particularly large effect of competition on productivity. This is inconsistent with the selection effect hypothesis.

Table 6also presents $p$ values for the hypothesis that the coefficients on the polynomial series approximating $g^{(k)}(\cdot)$ are jointly zero. This is a test of the null that the order statistic bias 
is negligible. Consistent with the understanding above, I find that we can reject the null hypothesis for $k$ very small or $k$ very large, and further that the order statistic bias plays a larger role for HHI numbers-equivalent measures of competition. This is intuitive - the two non-HHI measures of competition are more mechanically correlated with the number of establishments in a market.

It is important to observe that results from the quantile approach do not decisively rule out the existence of a selection effect. I am only able to identify and quantify the contribution of the selection effect, as I did in Section 5.1, by supplementing the econometrics with assumptions about the establishments' exit decision problem. In contrast with that approach, which found zero role for the selection effect, what the quantile analysis tells us is that the selection effect is insufficient to explain the features of the data- in particular, that establishments in the upper quantiles of the productivity distribution, those theory tells us should be least likely to exit, exhibit productivity gains on par with those of the lower quantiles when competition increases. While this does not rule out the selection effect entirely, it does suggest that the treatment effect is operative for some establishments.

\section{Robustness and Other Considerations}

In this section I document several first-order robustness checks. Returns to scale could explain much of the findings of Section 4.1, that competition is correlated with productivity, and so in Section 6.1 I develop a test to rule this mechanism out. Second, in 6.2, I consider a number of alternative specifications. Section 6.3 endeavors to generalize the results using the grouped quantile approach. Finally, I also offer, in Section 6.4, evidence from my data on potential within-firm mechanisms driving the result that the correlation between productivity and competition is primarily a treatment effect. However, this evidence is incomplete; it is meant primarily to suggest interesting avenues for future research.

\subsection{Returns to Scale}

In Section 3.4 I assumed constant returns to scale in order to use input shares to measure productivity. By that construction, I obtained elasticities $\alpha$ and used them to derive productivity residuals $\omega$. Consistent with this, define $\hat{q}_{i t}$ to be the constant returns to scale 
predicted output:

$$
\hat{q}_{i t}=\alpha_{L t} l_{i t}+\alpha_{K^{E} t} k_{i t}^{E}+\alpha_{K^{S} t} k_{i t}^{S}+\alpha_{M t} m_{i t}+\alpha_{E t} e_{i t} .
$$

Suppose, however, that the true model involves returns to scale of order $\gamma$. Now,

$$
q_{i t}=(1+\gamma) \hat{q}_{i t}+\tilde{\omega}_{i t}
$$

- where $\tilde{\omega}_{i t}$ is the true productivity term. Rearranging equation 15 and taking expectations the relationship to productivity, as measured in Section 3.4, becomes clearer:

$$
\mathbb{E}\left[q_{i t}-\hat{q}_{i t}\right]=\mathbb{E}\left[\tilde{\omega}_{i t}\right]+\gamma \hat{q}_{i t}
$$

The left-hand side of this equation corresponds to actual output net of predicted output under CRS. It suggests a simple approach to measuring $\gamma$ : regress $\omega_{i t}$, as constructed in Section 3.4, on CRS predicted output. Predicted output is of course endogenous, but my market demand shifters from Section 3.3 are natural instruments for scale. Model (1) of Table 7 presents results for this IV regression. At first glance, the coefficient of $\hat{\gamma}=0.0985$ suggests increasing returns to scale, which would trivialize the correlation between productivity and competition. However, note well the results for the over-identification test, which strongly reject the hypothesis that the instruments are not having a treatment effect on the outcome variable. Indeed, this is consistent with the maintained hypothesis of the paper- if our demand shifters are having an effect on productivity via competition, this would invalidate them as instruments for the regression of $\omega$ on predicted output. In models (2) - (5) I resolve this problem by adding $c_{m(i) t}$ as a regressor, with the result that the returns to scale parameter disappears.

This result is of independent interest: it suggests that if we take a purely physical approach to measuring productivity, ignoring market conditions, we might mistake the productivity effects of competition for increasing returns to scale; a production-side analogue of the scale estimator bias discussed in Klette and Giliches (1996). 
Table 7: Returns to Scale Results

\begin{tabular}{lccccc}
\hline & \multicolumn{5}{c}{ Dependent Variable: $\omega_{i t}$} \\
& $(1)$ & $(2)$ & $(3)$ & $(4)$ & $(5)$ \\
\hline Scale Coeff. $\left(\hat{q}_{i t}\right)$ & $0.0985^{*}$ & -0.0273 & -0.0139 & -0.0392 & -0.0131 \\
& $(0.0172)$ & $(0.0311)$ & $(0.0287)$ & $(0.0353)$ & $(0.0319)$ \\
$\log \left(\right.$ No. Estab./mi. $\left.{ }^{2}\right)$ & & $0.0556^{*}$ & & & \\
& & $(0.0121)$ & & & \\
$\log \left(\right.$ No. Firms/mi. $\left.{ }^{2}\right)$ & & & $0.0539^{*}$ & & \\
& & & $(0.0122)$ & & \\
$\log \left(\right.$ HHI No. Estab./mi. $\left.{ }^{2}\right)$ & & & & $0.0615^{*}$ & \\
& & & & $(0.0137)$ & \\
$\log \left(\right.$ HHI No. Firms/mi. $\left.{ }^{2}\right)$ & & & & & $0.0613^{*}$ \\
& & & & & $(0.0161)$ \\
\hline Observations (rounded) & 7400 & 7400 & 7400 & 7400 & 7400 \\
Clusters (rounded) & 300 & 300 & 300 & 300 & 300 \\
$R^{2}$ & 0.0000 & 0.1122 & 0.1094 & 0.1018 & 0.0947 \\
Hansen J Statistic & 20.5482 & 1.5197 & 1.0716 & 1.3913 & 0.6728 \\
$\quad p$ Value & 0.0000 & 0.2177 & 0.3131 & 0.2382 & 0.4121 \\
\hline
\end{tabular}

Notes: Here I present IV results for the effect of scale and competition on productivity residuals, as discussed in Section 6.1 In model (1) scale is the only dependent variable; models (2)-(5) include the four alternative competition indices as well. Yearspecific fixed effects are included but not reported, and standard errors (in parentheses) are clustered at the CEA level. Hansen $\mathrm{J}$ (over identification) test statistics are reported with associated $\mathrm{p}$ values. For reference, ${ }^{*}$ signifies $p \leq 0.05$. 
Table 8: Alternative Specification Results

\begin{tabular}{|c|c|c|c|c|c|c|}
\hline & \multicolumn{6}{|c|}{ Dependent Variable: $\omega_{i t}$} \\
\hline & (1) & $(2)$ & $(3)$ & (4) & $(5)$ & (6) \\
\hline \multirow[t]{2}{*}{$\log \left(\right.$ No. Estab. $\left./ \mathrm{mi}^{2}{ }^{2}\right)$} & $0.0434^{*}$ & $0.0446^{*}$ & $0.0409^{*}$ & 0.0625 & $0.0431^{*}$ & $0.0443^{*}$ \\
\hline & $(0.0071)$ & $(0.0078)$ & $(0.0062)$ & $(0.0849)$ & $(0.0068)$ & $(0.0058)$ \\
\hline \multirow[t]{2}{*}{$\log \left(\right.$ No. Firms $\left./ \mathrm{mi}^{2}{ }^{2}\right)$} & $0.0467^{*}$ & $0.0459^{*}$ & $0.0425^{*}$ & 0.0569 & $0.0454^{*}$ & $0.0471^{*}$ \\
\hline & $(0.0079)$ & $(0.0086)$ & $(0.0069)$ & $(0.0876)$ & $(0.0077)$ & $(0.0065)$ \\
\hline \multirow[t]{2}{*}{$\log \left(\right.$ HHI No. Estab./mi. $\left.{ }^{2}\right)$} & $0.0435^{*}$ & $0.0434^{*}$ & $0.0392^{*}$ & 0.0747 & $0.0443^{*}$ & $0.0446^{*}$ \\
\hline & $(0.0071)$ & $(0.0075)$ & $(0.0060)$ & $(0.0895)$ & $(0.0069)$ & $(0.0059)$ \\
\hline \multirow[t]{2}{*}{$\log \left(\right.$ HHI No. Firms $\left./ \mathrm{mi}^{2}\right)$} & $0.0518^{*}$ & $0.0492^{*}$ & $0.0418^{*}$ & 0.0643 & $0.0517^{*}$ & $0.0518^{*}$ \\
\hline & $(0.0097)$ & $(0.0105)$ & $(0.0080)$ & $(0.0832)$ & $(0.0096)$ & $(0.0084)$ \\
\hline Observations (rounded) & 5000 & 5900 & 7100 & 7400 & 4200 & 7400 \\
\hline Clusters (rounded) & 300 & 300 & 300 & 300 & 300 & 300 \\
\hline
\end{tabular}

Notes: Here I consider alternative specification results for the effect of competition on productivity residuals. Note that each cell represents an independent regression. Model (1) uses five-year lagged instruments; Model (2) uses only CEAs with 10 or more plants; Model (3) uses additional instruments (see text); Model (4) is the within-firm estimator; Model (5) is the betweencounty estimator, and finally Model (6) uses a revenue-based productivity residual. Year-specific constants are included but not reported and standard errors (in parentheses) are clustered at the CEA level. For reference, ${ }^{*}$ signifies $p \leq 0.05$.

\subsection{Alternative Specifications}

In this section I present a number of alternative specifications for the instrumental variables results from Table 2, Results for the alternative specifications are presented in Table 8 for each of the four measures of competition; note that each coefficient estimate reported is from a distinct regression.

In Model (1) I report IV results for the same regression with 5-year lagged instruments. This is meant to address the concern that contemporaneous demand shifters may be poor instruments for long-run demand shocks if convergence is slow. Alternatively, Model (2) restricts attention to CEAs in which there are 10 or more ready-mix concrete plants, to guarantee that the results are not driven by low-density markets. Model (3) uses additional instruments: county employment in construction-related industries per square mile, population per square mile, and the number of $5+$ family building permits per square mile. For each of these specifications, (1)-(3) I find no substantive deviation from the main results of Table 2.

In order to more carefully examine the source of variation, model (4) reports the withinplant regression. This is identified exclusively off of the within-market time series variation; the value of the coefficient is consistent with my other results, but the there is insufficient variation to obtain a statistically significant estimate. This suggests that most of the iden- 
Table 9: Installed Capacity

\begin{tabular}{lccccc}
\hline & \multicolumn{2}{c}{ OLS } & & \multicolumn{2}{c}{ IV } \\
\cline { 2 - 3 } \cline { 5 - 6 } & $(1)$ & $(2)$ & & $(3)$ & $(4)$ \\
\hline $\log ($ Structural Capital/mi. & & \\
& 0.0243 & & & 0.0340 & \\
& $(0.0042)$ & & & $(0.0045)$ & \\
$\log ($ Equipment Capital/mi. & & & \\
& & 0.0234 & & & 0.0334 \\
& & $(0.0042)$ & & $(0.0044)$ \\
\hline Observations & 7400 & 7400 & & 7400 & 7400 \\
Clusters & 300 & 300 & & 300 & 300 \\
$R^{2}$ & 0.1086 & 0.1085 & & 0.1076 & 0.1073 \\
First-Stage F & & & & 852.2 & 895.7 \\
$\mathrm{p}$ Value & & & & 0 & 0 \\
Hansen J Statistic & & & & 5.726 & 5.589 \\
$\mathrm{p}$ Value & & & 0.0571 & 0.0611 \\
\hline
\end{tabular}

Notes: Year-specific constants are included but not reported and standard errors (in parentheses) are clustered at the CEA

level. For reference, ${ }^{*}$ signifies $p \leq 0.05$.

tifying variation in my main regressions is between county. Model (5) reports results for the between-county regression (i.e., with county fixed effects) that are consistent with my earlier results.

Finally, model (6) reports results for a specification where $\omega_{i t}$ is calculated using plant revenues instead of physical output. This is important because the availability of physical output data is special to ready-mix concrete and a handful of other industries; the fact that the result is similar offers some reassurance about the extension of these methods to other industries.

\subsection{Generality: Cross-Industry Comparisons}

Are the results above special to ready-mix concrete? While this industry offers a unique opportunity to carefully and rigorously identify the objects of interest, we might worry that the results do not generalize. Here I attempt a partial remedy for this concern by extending the quantile approach of Section 5.2 to the cross-industry design. I borrow heavily here from Syverson (2004b) - where that paper asks whether lower deciles of the within-industry productivity distribution respond to greater competition, here I ask whether the upper deciles do as well. 
Table 10: Effects at the Four-digit SIC code level

\begin{tabular}{lcccccc}
\hline & & \multicolumn{3}{c}{ Dependent Variable: } \\
& Median & Dispersion & 10th \%tile & 20th \%tile & 80 th \%tile & 90th \%tile \\
& $(1)$ & $(2)$ & $(3)$ & $(4)$ & $(5)$ & $(6)$ \\
\hline Value/lb. & 0.0033 & $-0.0005^{*}$ & 0.0028 & 0.0030 & 0.0032 & 0.0037 \\
& $(0.0026)$ & $(0.0002)$ & $(0.0021)$ & $(0.0023)$ & $(0.0030)$ & $(0.0030)$ \\
PPSR & $0.7318^{*}$ & -0.1348 & 0.7568 & $0.7826^{*}$ & $0.8075^{*}$ & $0.8903^{*}$ \\
& $(0.3626)$ & $(0.0696)$ & $(0.3180)$ & $(0.3405)$ & $(0.3780)$ & $(0.3922)$ \\
Ad. Ratio & -0.2919 & $0.2988^{*}$ & -1.5070 & -1.0910 & -0.0437 & 0.2869 \\
& $(0.7646)$ & $(0.1413)$ & $(0.7518)$ & $(0.7270)$ & $(0.7640)$ & $(0.8421)$ \\
\hline Observations (rounded) & 400 & 400 & 400 & 400 & 400 & 400 \\
$R^{2}$ & 0.0287 & 0.0195 & 0.0428 & 0.0393 & 0.0268 & 0.0312 \\
\hline
\end{tabular}

Notes: This table presents results from an OLS regression of the relevant moment or quantile of the productivity residual distribution, computed at the four-digit SIC level, on measures of substitutability, as detailed in Section 6.3 Robust standard errors are presented in parentheses. For reference, ${ }^{*}$ signifies $p \leq 0.05$.

I adopt the quantile approach of Section 5.2 with two important differences. First, a market is defined by a four-digit SIC code. Productivity is computed at the establishment level as detailed for RMC in Section 3.4, with elasticities computed at the year-SIC level. Second, there is no measure of competition at this level of aggregation. Instead, I regress quantiles of the distribution of productivity directly on variables that are meant to capture the intensity of competition in a market. These include the value per pound, which captures the costs of transportation; the primary product specialization ratio (PPSR), which is the fraction of revenues generated by the "primary product" of the establishment, similar to the revenue fraction in Section 6.4, and then the ratio of advertising expenditures to revenues.

Results are presented in Table 10. Models (1)-(4) are primarily replications of Syverson (2004b) and are consistent with their results. However these models do not help us think about the question of selection versus treatment: while a decrease in dispersion is consistent with greater selection in more competitive markets, the prediction of the treatment effect model is ambiguous. A more direct test, consistent with the argument of Section 5.2, is offered in models (5) and (6). There, for value/lb and PPSR we see that greater competition affects not only the lower deciles of the productivity distribution but also the higher ones, a comparative static that is not generated by the selection model. For the advertising ratio we see the opposite result, but this should not be surprising, since advertising is the classic example of endogenous sunk costs, in the spirit of Sutton (1991). Moreover, here we use TFPR rather than TFPQ, and we might expect advertising to grow the dispersion of measured TFPR mechanically. 


\subsection{Mechanisms}

If the relationship between competition and productivity is governed by a mechanism that functions like a treatment effect, rather than the selection effect generated by industry dynamics models, where should we look to understand it? In this section I revisit the instrumental variables regression design from Section 4.1 and estimate

$$
y_{i t}=\beta_{t}+\beta c_{m(i) t}+\varepsilon_{i t}
$$

- where $y_{i t}$ stands in for a host of left-hand side variables that capture firm behavior and may help to explain how firms in more competitive markets reorganize to increase output. Table 11 presents results where $y_{i t}$ stands in for the ratio of RMC revenues to total revenus, capturing specialization, and several factor input ratios: non-productive to productive labor hours, labor to capital, and equipment capital to structural capital.

The results paint a coherent picture: in more competitive markets, RMC firms are more specialized, as we see from models (1)-(4). They spend relatively more hours on management ("non-productive labor"), per models (5)-(8), which suggests that much of the relative decline in labor expenditures, see models (9)-(12) is coming from productive labor hours. Though statistically marginal, in models (13)-(16) it also appears that there is greater expenditure on equipment rather than structural capital. This last result may be an artifact of the first, as RMC trucks are equipment capital.

Combined, these results suggest that the answer lies in management rather than capacity utilization. If capacity utilization were the story, then we would expect to see the labor share of variable inputs such as labor share to be positively rather than negatively correlated with competition driven by demand shocks. The positive correlation with the ratio of nonproductive to productive labor hours supports the hypothesis that better management is improving productivity. But how? In Appendix Section A.3 I introduce data from the Management and Organizational Practices Survey, but find no leads.

This leaves the question open for future work, but not without guidance. Based on my findings in Section 6.1 above, the mechanism does not induce returns to scale, which eliminates traditional stories consistent with Sutton (1991) endogenous sunk costs: advertisement and investment in reductions in variable cost. Moreover, we have ruled out capacity utilization 
Table 11: Alternative Dependent Variables

Dependent Variable:

\begin{tabular}{|c|c|c|c|c|c|c|c|c|}
\hline & \multicolumn{4}{|c|}{ RMC to Total Revenue Ratio } & \multicolumn{4}{|c|}{ Non- to Productive Labor Ratio } \\
\hline & (1) & $(2)$ & (3) & (4) & $(5)$ & (6) & (7) & (8) \\
\hline $\log \left(\right.$ No. Estab. $/$ mi. $^{2}$ ) & $\begin{array}{c}0.0142^{*} \\
(0.0035)\end{array}$ & & & & $\begin{array}{c}0.0195^{*} \\
(0.0058)\end{array}$ & & & \\
\hline $\log \left(\right.$ No. Firms $/$ mi. $\left.^{2}\right)$ & & $\begin{array}{l}0.0150^{*} \\
(0.0038)\end{array}$ & & & & $\begin{array}{l}0.0222^{*} \\
(0.0063)\end{array}$ & & \\
\hline $\log \left(\right.$ HHI No. Estab./mi. $\left.{ }^{2}\right)$ & & & $\begin{array}{c}0.0143^{*} \\
(0.0036)\end{array}$ & & & & $\begin{array}{c}0.0187^{*} \\
(0.0057)\end{array}$ & \\
\hline $\log \left(\right.$ HHI No. Firms/mi. $\left.{ }^{2}\right)$ & & & & $\begin{array}{c}0.0170^{*} \\
(0.0044)\end{array}$ & & & & $\begin{array}{c}0.0251^{*} \\
(0.0070)\end{array}$ \\
\hline Observations (rounded) & 7400 & 7400 & 7400 & 7400 & 7400 & 7400 & 7400 & 7400 \\
\hline Clusters (rounded) & 300 & 300 & 300 & 300 & 300 & 300 & 300 & 300 \\
\hline First-Stage F & 344.5 & 196.3 & 171.4 & 48.7 & 344.3 & 196.2 & 171.1 & 48.7 \\
\hline p Value & 0 & 0 & 0 & 0 & 0 & 0 & 0 & 0 \\
\hline Hansen J Statistic & 2.048 & 2.015 & 2.423 & 2.377 & 3.454 & 2.878 & 4.207 & 3.266 \\
\hline \multirow[t]{4}{*}{$\mathrm{p}$ Value } & 0.3591 & 0.3651 & 0.2977 & 0.3046 & 0.1778 & 0.2371 & 0.1220 & 0.1953 \\
\hline & \multicolumn{8}{|c|}{ Dependent Variable: } \\
\hline & \multicolumn{4}{|c|}{ Labor to Capital Ratio } & \multicolumn{4}{|c|}{ Equipment to Structural Capital Ratio } \\
\hline & (9) & $(10)$ & $(11)$ & $(12)$ & (13) & $(14)$ & (15) & $(16)$ \\
\hline $\log \left(\right.$ No. Estab. $/ \mathrm{mi}^{2}$ ) & $\begin{array}{c}-0.0075^{*} \\
(0.0019)\end{array}$ & & & & $\begin{array}{l}0.5173^{*} \\
(0.2452)\end{array}$ & & & \\
\hline $\log \left(\right.$ No. Firms $\left./ \mathrm{mi}^{2}\right)$ & & $\begin{array}{c}-0.0081^{*} \\
(0.0020)\end{array}$ & & & & $\begin{array}{c}0.4709 \\
(0.2672)\end{array}$ & & \\
\hline $\log \left(\right.$ HHI No. Estab./mi. $\left.{ }^{2}\right)$ & & & $\begin{array}{c}-0.0076^{*} \\
(0.0020)\end{array}$ & & & & $\begin{array}{c}0.5463^{*} \\
(0.2269)\end{array}$ & \\
\hline $\log \left(\right.$ HHI No. Firms/mi. $\left.{ }^{2}\right)$ & & & & $\begin{array}{c}-0.0095^{*} \\
(0.0024)\end{array}$ & & & & $\begin{array}{c}0.5688 \\
(0.2965)\end{array}$ \\
\hline Observations (rounded) & 7400 & 7400 & 7400 & 7400 & 7400 & 7400 & 7400 & 7400 \\
\hline Clusters (rounded) & 300 & 300 & 300 & 300 & 300 & 300 & 300 & 300 \\
\hline First-Stage F & 344.5 & 196.3 & 171.4 & 48.7 & 344.5 & 196.3 & 171.4 & 48.7 \\
\hline p Value & 0 & 0 & 0 & 0 & 0 & 0 & 0 & 0 \\
\hline Hansen J Statistic & 1.548 & 1.330 & 1.721 & 1.349 & 1.364 & 2.014 & 0.697 & 1.526 \\
\hline p Value & 0.4610 & 0.5140 & 0.4229 & 0.5092 & 0.5056 & 0.3652 & 0.7057 & 0.4661 \\
\hline
\end{tabular}

Notes: Here I consider alternative specifications of the IV regressions with different left-hand side variables, as detailed in Section 6.4 Year-specific constants are included but not reported and standard errors (in parentheses) are clustered at the CEA level. Instruments include the number of building permits per square mile, the number of single family building permits per square mile, and local government road and highway expenditure per square mile. For reference, ${ }^{*}$ signifies $p \leq 0.05$.

here. Finally, the story seems to depend on management. One hypothesis that would be consistent with the above is that having competitors, and observing those competitors, generates information that allows me to better disentangle signals and monitor my own workers. Therefore less competitive markets create room for managerial slack (Nalebuff and Stiglitz, 1983). What form does this managerial slack take? It may be that this takes the form of direct wastage: in the ready-mix concrete business, hardened concrete on the inside of a 
Table 12: Decomposed Effect of a Standard Deviation Increase in $c_{m(i) t}$

\begin{tabular}{|c|c|c|c|c|}
\hline \multirow[b]{2}{*}{ Model } & \multirow[b]{2}{*}{ Output } & \multicolumn{3}{|c|}{ Attributable to } \\
\hline & & Covariance & Treatment & Selection \\
\hline $\log \left(\right.$ No. Estab. $\left./ \mathrm{mi}^{2}{ }^{2}\right)$ & $3.98 \%$ & $0.25 \%$ & $3.39 \%$ & $0.34 \%$ \\
\hline $\log \left(\right.$ No. Firms $\left./ \mathrm{mi}^{2}\right)$ & $4.05 \%$ & $0.23 \%$ & $3.47 \%$ & $0.35 \%$ \\
\hline $\log \left(\right.$ HHI No. Estab. $\left./ \mathrm{mi}^{2}\right)$ & $4.13 \%$ & $0.30 \%$ & $3.80 \%$ & $0.04 \%$ \\
\hline $\log \left(\right.$ HHI No. Firms $/$ mi. $\left.^{2}\right)$ & $4.36 \%$ & $0.26 \%$ & $3.82 \%$ & $0.29 \%$ \\
\hline
\end{tabular}

Notes: Here I present a decomposition of the effect of a one standard deviation increase in the competition index on physical output into its constituent parts: the covariance of output and marketshare (or "reallocation"), the treatment effect of competition on productivity, and the selection effect driven by greater exit of unproductive establishments. Estimates are based on a one standard deviation increase in 1987, per Table 1 as well as coefficient estimates from Tables 4 and 5

drum, which is costly to extract. Alternatively, and consistent with the relative reduction of productive labor hours, it may be that in more competitive markets, the reduction of managerial slack means cutting other slack, i.e. firing unproductive (but not non-productive) workers. Based on the results here, this organizational focus appears to be the right direction to push future research on the relationship between competition and productivity.

\section{Discussion}

The objective of this paper has been to test two competing hypotheses that could explain the positive correlation between productivity and competition. Nested in each of these hypotheses - the treatment effect and the selection effect of competition — is a vast theoretical literature, so it is a first-order question to know which is consistent with the data. I have offered three pieces of evidence on this point: a semi-parametric selection correction, a grouped IV quantile approach, and a direct test of the reallocation hypothesis in ready-mix concrete. All of my evidence points to the conclusion that competition has a treatment effect on measured productivity.

Combining the decomposition in Section 4.2 with the structural estimates in Section 5.1 , I can model the effect of a one-standard deviation change in competitiveness. In Table 12 I show how, across my different specifications, this increase affects productivity through different channels. For all specifications, output increases by approximately 4\%. Less than a tenth of that comes through changes in the covariance between productivity and competition, i.e. the reallocation channel. And since differential selection is the extensive margin of reallocation, it too explains less than a tenth of the increase in output. The bulk of the change is coming 
through the treatment effect channel.

Of late there has been great public interest in understanding the apparent rise of market power across many industries (Eekhout et al., 2018) and the implications of this apparent rise for productivity in America. These results suggest that rather than focusing on the reallocative power of competitive markets, the salient mechanisms are to be found by looking within the firm. 


\section{References}

Ackerberg, D., Caves, K., and Frazer, G. (2015). Identification properties of recent production function estimators. Econometrica, 83(6):2411-2451. Working Paper.

Adelman, M. A. (1969). Comment on the "h" concentration measure as a numbersequivalent. Review of Economics and Statistics, 51(1):99-101.

Asker, J., Collard-Wexler, A., and De Loecker, J. K. (2014). Dynamic inputs and resource (mis)allocation. Journal of Political Economy, 122(5):1013-1063.

Asplund, M. and Nocke, V. (2006). Firm turnover in imerfectly competitive markets. Review of Economic Studies, 73(2):295-327.

Baily, M., Hulten, C., and Campbell, D. (1992). Productivity dynamics in manufacturing plants. Brookings Papers on Economic Activity: Microeconomics, 4:187-267.

Barseghyan, L. and DiCecio, R. (2011). Entry costs, industry structure, and cross-country income and tfp differences. Journal of Economic Theory, 146(5):1828-1851.

Bartelsman, E. J. and Doms, M. (2000). Understanding productivity: Lessons from longitudinal microdata. Journal of Economic Literature, 38(3):569-594.

Bloom, N., Brynjolfsson, E., Foster, L., Jarmin, R. S., Patnaik, M., Saporta-Eksten, I., and Van Reenen, J. (2017). What drives differences in managment? NBER Working Ppaer no. 23300.

Bloom, N., Draca, M., and Van Reenen, J. (2016). Trade induced technical change? the impact of chinese imports on innovation, it and productivity. Review of Economic Studies, $83(1): 87-117$.

Boone, J. (2008). A new way to measure competition. The Economic Journal, 118(531):12451261.

Bottasso, A. and Sembenelli, A. (2001). Market power, productivity, and the eu single market program: Evidence from a panel of italian firms. European Economic Review, 45(1):167-186.

Caves, R. and Barton, D. (1990). Efficiency in US Manufacturing Industries. MIT Press.

Chernozhukov, V. and Hansen, C. B. (2005). An iv model of quantile treatment effects. Econometrica, 73(1):245-261. 
Chetverikov, D., Larsen, B., and Palmer, C. (2013). Iv quantile regression for group-level treatments, with an application to the effects of trade on the distribution of wages. Working Paper.

Collard-Wexler, A. (2011). Productivity dispersion and plant selection in hte ready-mix concrete industry. Working Paper.

Collard-Wexler, A. (2013). Demand fluctuations in the ready-mix concrete industry. Econometrica, 81(3):1003-1037.

Collard-Wexler, A. and De Loecker, J. K. (2015). Reallocation and technology: Evidence from the us steel industry. American Economic Review, 105(1):131-171. Working Paper.

De Loecker, J. K. and Warzynski, F. (2012). Markups and firm-level export status. American Economic Review, 102(6):2437-2471.

Dertouzos, M. L., Lester, R., and Solow, R. M. (1989). Made in America: Regaining the Productive Edge. MIT Press, Cambridge, MA.

Doraszelski, U. and Satterthwaite, M. (2010). Computable markov-perfect industry dynamics. The RAND Journal of Economics, 41(2):215-243.

Dunne, T., Klimek, S., and Schmitz, J. (2010). Competition and productivity: Evidence from the post wwii us cement industry. Working Paper.

Eekhout, J., De Loecker, J., and Unger, G. (2018). The rise of markups. Working Paper.

Ericson, R. and Pakes, A. (1995). Markov-perfect industry dynamics: A framework for empirical work. Review of Economic Studies, 62(1):53-82.

Fabrizio, K. R., Rose, N. L., and Wolfram, C. D. (2007). Do markets reduce costs? assessing the impact of regulatory restructuring on us electric generation efficiency. American Economic Review, 97(4):1250-1277.

Foster, L., Haltiwanger, J., and Krizan, C. J. (2001). Aggregate Productivity Growth: Lessons from Microeconomic Evidence, volume New Developments in Productivity Analysis, pages 303-372. University of Chicago Press.

Foster, L., Haltiwanger, J., and Syverson, C. (2008). Reallocation, firm turnover, and efficiency: Selection on productivity or profitability? American Economic Review, 98(1):394425. 
Graham, D. R., Kaplan, D. P., and Sibley, D. S. (1983). Efficiency and competition in the airline industry. Bell Journal of Economics, 14:118-38.

Green, A. and Mayes, D. (1991). Technical inefficiency in manufacturing industries. The Economic Journal, 101(406):523-538.

Hay, D. A. and Liu, G. S. (1997). The efficiency of firms: What difference does competition make? The Economic Journal, 107(442):597-617.

Hicks, J. R. (1935). Annual survey of economic theory: The theory of monopoly. Econometrica, 3(1):1-20.

Holmes, T. J. and Schmitz, J. A. (2010). Competition and productivity: A review of evidence. Annual Review of Economics, 2:619-642.

Holmström, B. (1982). Moral hazard in teams. Bell Journal of Economics, 13(2):324-340.

Hopenhayn, H. A. (1992). Entry, exit, and firm dynamics in long run equilibrium. Econometrica, 60(5):1127-1150.

Johnson, K. P. (1995). Redefinition of the bea economic areas. Survey of Current Business, $75: 75-81$.

Klette, T. J. and Giliches, Z. (1996). The inconsistency of common scale estimators when output prices are unobserved and endogenous. Journal of Applied Econometrics, 11:343361.

Kneller, R. and McGowan, D. (2014). Productivity-enhancing demand shocks: Technology adoption during the u.s. ethanol boom: Technology adoption during the u.s. ethanol boom. Working Paper.

Leibenstein, H. (1966). Allocative efficiency vs. "x-efficiency". American Economic Review, $56(3): 392-415$.

Levinsohn, J. and Petrin, A. (2003). Estimating production functions using inputs to control for unobservables. Review of Economic Studies, 70(2):317-342.

Melitz, M. (2003). The impact of trade on intra-industry reallocations and aggregate industry productivity. Econometrica, 71(6):1695-1725.

Melitz, M. and Ottaviano, G. (2008). Market size, trade, and productivity. Review of Economic Studies, 75:295-316. 
Melitz, M. and Polanec, S. (2013). Dynamic olley-pakes productivity decomposition with entry and exit. Working Paper.

Nalebuff, B. and Stiglitz, J. (1983). Information, competition, and markets. American Economic Review, 73(2):278-283.

Neyman, J. and Scott, E. L. (1948). Consistent estimates based on partially consistent observations. Econometrica, 16(1):1-32.

Nickell, S. J. (1996). Competition and corporate performance. Journal of Political Economy, 104(4):724-746.

Olley, G. S. and Pakes, A. (1996). The dynamics of productivity in the telecommunications equipment industry. Econometrica, 64(6):1263-1297.

Pavcnik, N. (2002). Trade liberalization, exit, and productivity improvements: Evidence from chilean plants. Review of Economic Studies, 69(1):245-276.

Perelman, M. (2011). Retrospectives: X-efficiency. Journal of Economic Perspectives, $25(4): 211-222$.

Porter, M. E. (1990). The Competitive Advantage of Nations. Macmillan, London.

Raith, M. (2003). Competition, risk, and managerial incentives. American Economic Review, 93(4):1425-1436.

Schmidt, K. M. (1997). Managerial incentives and product market competition. Review of Economic Studies, 64(2):191-213.

Schmitz, J. (2002). Competitive pressure and labor productivity: World iron ore markets in the 1980s. American Economic Review, 92(4):745-760.

Schmitz, J. (2005). What determines productivity? lessons from the dramatic recovery of the u.s. and canadian iron ore industries following their early 1980s crisis. Journal of Political Economy, 113(3):582-625.

Sivadasan, J. (2009). Barriers to competition and productivity: Evidence from india. The B.E. Journal of Economic Analysis 6 Policy, 9(1):1-66.

Stigler, G. J. (1976). The xistence of x-efficiency. American Economic Review, 66(1):213-216.

Sutton, J. (1991). Sunk Costs and Market Structure: Price Competition, Advertising, and the Evolution of Concentration. MIT Press. 
Syverson, C. (2004a). Market structure and productivity: A concrete example. Journal of Political Economy, 112(6):1181-1222.

Syverson, C. (2004b). Product substitutability and productivity dispersion. Review of Economics and Statistics, 86(2):534-550.

Syverson, C. (2008). Markets: Ready-mixed concrete. Journal of Economic Perspectives, $22(1): 217-234$.

Williamson, O. E. (1968). Economies as an antitrust defense: The welfare tradeoffs. American Economic Review, 58(1):18-36. 


\section{Appendices}

\section{A Empirical Appendix}

\section{A.1 Data}

There are over five thousand ready-mix concrete establishments observed by the Census of Manufactures in each year of my sample. Unfortunately, roughly one-third of these establishments are "administrative records" establishments; that is, small enough to be exempt from completing long-form census surveys. Census data for these establishments do exist, but they are generated from a combination of administrative records from other agencies and imputation, the latter of which makes them unusable for establishment-level productivity analysis. I therefore exclude all establishments that fall into this category.

A second constraint is that a small handful of establishments in my sample are extensively diversified and operate in multiple SIC codes. This makes it difficult to construct a productivity residual for the ready-mix concrete portion of their business because data on their inputs are pooled at the establishment level, across all lines of production. I deal with this by excluding establishments for which less than fifty percent of their total sales is from readymix concrete. For diversified establishments that survive this exclusion, inputs devoted to ready-mix concrete are approximated by scaling the conflated input variable by the fraction of sales revenue from ready-mix concrete.

Finally, I measure the establishment-level price of a cubic yard of concrete by dividing sales by quantity. I observe a small number of firms with extremal values, presumably generated by misreporting, and exclude them from the sample.

It is important to note that while these establishments are excluded for regressions that depend on estimates of the productivity residuals, they are not excluded in the calculation of market-level variables; in particular, the competition indexes discussed below in Section 3.3 use data for all establishments.

In order to construct production function residuals as described in Section 3.4. I use data from the Census of Manufactures at the establishment level for inputs, including energy, materials, 
Table A-1: Production Function Parameters

\begin{tabular}{cccccc}
\hline \hline & $\alpha_{L t}$ & $\alpha_{K^{S} t}$ & $\alpha_{K^{E} t}$ & $\alpha_{M t}$ & $\alpha_{E t}$ \\
\cline { 2 - 6 } 1982 & 0.2250 & 0.0101 & 0.0193 & 0.7173 & 0.0283 \\
1987 & 0.2217 & 0.0227 & 0.0456 & 0.6889 & 0.0210 \\
1992 & 0.2403 & 0.0176 & 0.0436 & 0.6737 & 0.0248 \\
\hline \hline
\end{tabular}

Notes: This table presents production function parameter estimates, which are used in the construction of $\omega_{i t}$. See Section 3.4 for discussion, and Foster et al. (2008) for further details on estimation.

equipment capital, structural capital, and labor. Energy and materials inputs are captured by expenditures reported by the Census of Manufactures divided by two-digit deflators from the NBER productivity database. Equipment and structural capital are the reported book value multiplied by two-digit capital rental rates from the Bureau of Labor statistics. Finally, labor is taken as the number of production labor hours multiplicatively adjusted by the ratio of total wages to production wages. Production function input elasticities for the RMC industry are presented in Table A-1.

\section{A.2 Additional Tables}

In this section I offer supplementary tables from the analysis of the RMC industry. Table A-2 documents the first-stage regressions that are employed throughout the paper. Tables A-4. A-5, and A-6 replicate the main tables of the body of the paper using labor productivity in place of TFPQ. Labor productivity is computed as the ratio of total quantity output to adjusted labor inputs. Finally, Table A-7 weakens Assumption 2 slightly to allow for a second-order Markov process. Since I only have three time periods of data, this collapses the dataset to a single period.

\section{A.2.1 First-Stage Regressions}

Here I present the first-stage regressions for the IV strategy used throughout the paper. Estimates are reported in Table A-2. Conditional on the total number or building permits, the negative coefficient on the number of single-family building permits is intuitive, since it implies fewer larger dwellings.

Appendix-2 
Table A-2: First-Stage Regressions

\begin{tabular}{|c|c|c|c|c|}
\hline & $\begin{array}{c}(1) \\
\log \left(\text { No. Estab. } / \text { mi. }^{2}\right)\end{array}$ & $\begin{array}{l}(2) \\
\log \left(\text { No. Firms } / \text { mi. }^{2}\right)\end{array}$ & $\begin{array}{c}(3) \\
\log \left(\text { HHI No. Estab. } / \text { mi. }^{2}\right)\end{array}$ & $\begin{array}{c}(4) \\
\log \left(\text { HHI No. Firms } / \text { mi. }^{2}\right)\end{array}$ \\
\hline Building Permits $/ \mathrm{mi}^{2}$ & $\begin{array}{c}0.1456 \\
(0.0743)\end{array}$ & $\begin{array}{c}0.1391 \\
(0.0878)\end{array}$ & $\begin{array}{c}0.2063 \\
(0.1062)\end{array}$ & $\begin{array}{c}0.1909 \\
(0.1213)\end{array}$ \\
\hline S.F. Building Permits $/ \mathrm{mi}^{2}$ & $\begin{array}{c}0.0143 \\
(0.0743)\end{array}$ & $\begin{array}{l}-0.0653 \\
(0.0892)\end{array}$ & $\begin{array}{l}-0.0138 \\
(0.1116)\end{array}$ & $\begin{array}{l}-0.1468 \\
(0.1364)\end{array}$ \\
\hline Road \& Hwy $\$ / \mathrm{mi}^{2}$ & $\begin{array}{l}0.4555^{*} \\
(0.0301)\end{array}$ & $\begin{array}{l}0.4963^{*} \\
(0.0336)\end{array}$ & $\begin{array}{l}0.4144^{*} \\
(0.0398)\end{array}$ & $\begin{array}{l}0.4451^{*} \\
(0.0572)\end{array}$ \\
\hline Observations (rounded) & 7400 & 7400 & 7400 & 7400 \\
\hline Clusters (rounded) & 300 & 300 & 300 & 300 \\
\hline$R^{2}$ & 0.7763 & 0.7191 & 0.6315 & 0.4647 \\
\hline
\end{tabular}

Notes: This table presents first-stage OLS regressions for the IV strategy used throughout the paper. Year-specific constants are included but not reported and standard errors (in parentheses) are clustered at the CEA level. For reference, * signifies $p \leq 0.05$.

\section{A.2.2 Survival Probits}

Here I consider probits predicting plant-level survival conditional on productivity and other variables, using the same IV strategy as in the rest of the paper. Results are presented in Table A-3.

On net, it appears that increased competition driven by shocks to market size have a positive, rather than a negative effect on survival. This would be consistent with a failure of the supermodularity condition described in Appendix Section B, which would make it possible for the exit threshold to decrease, rather than increase, but that would be a strong conclusion to draw here. More intuitively, we see a positive relationship between productivity and survival, as does the existing capital stock.

\section{A.2.3 Robustness: Labor Productivity}

As a robustness check, I revisit the main regressions of the paper using labor productivity instead of gross total factor productivity. Now, the productivity residual is given by the ratio of total physical output to adjusted labor inputs. Results are presented in Tables A-4, A-5, and A-6. The scale of the effects is different because now I am using a value-added production function instead of a gross production function, however, the qualitative results survive: the IV effects are larger than the OLS effects in the conflated, reduced-form approach; the largest effects are found in the highest deciles of the within-CEA productivity distribution, and the structural estimates of the selection effect of competition on productivity are a reasonably precise zero. 
Table A-3: Survival Probits

\begin{tabular}{lcccc}
\hline \multicolumn{5}{c}{ Dependent Variable: $\mathbb{1}(\text { survival })_{i t}$} \\
& $(1)$ & $(2)$ & $(3)$ & $(4)$ \\
\hline $\log \left(\right.$ No. Estab. $\left./ \mathrm{mi}^{2}{ }^{2}\right)$ & 0.0180 & & & \\
& $(0.0178)$ & & & \\
$\log \left(\right.$ No. Firms $\left./ \mathrm{mi}^{2}{ }^{2}\right)$ & & 0.0179 & & \\
& & $(.0185)$ & & \\
$\log \left(\right.$ HHI No. Estab. $\left./ \mathrm{mi.}^{2}\right)$ & & & 0.6685 & \\
& & & $(0.4797)$ & \\
$\log \left(\right.$ HHI No. Firms $\left./ \mathrm{mi.}^{2}\right)$ & & & & 0.4555 \\
& & & & $(0.5150)$ \\
$\omega_{i t}$ & 0.1962 & $0.1965^{*}$ & $0.1913^{*}$ & $0.1985^{*}$ \\
& $(0.0570)$ & $(0.0570)$ & $(0.0574)$ & $(0.0569)$ \\
Structural Capital & $0.0731^{*}$ & $0.0729^{*}$ & $0.0732^{*}$ & $0.0713^{*}$ \\
& $(0.0258)$ & $(0.0258)$ & $(0.0258)$ & $(0.0258)$ \\
Equipment Capital & $0.0549^{*}$ & $0.0551^{*}$ & $0.0543^{*}$ & $0.0562^{*}$ \\
& $(0.0254)$ & $(0.0254)$ & $(0.0254)$ & $(0.0253)$ \\
\hline Observations (rounded) & 8500 & 8500 & 8500 & 8500 \\
\hline
\end{tabular}

Notes: This table presents results from an IV probit of survival on a host of firm-specific variables. Survival here is a dummy for whether the firm appears in the LBD five years subsequent. For reference, ${ }^{*}$ signifies $p \leq 0.05$.

Table A-4: Labor Productivity: OLS and IV

\begin{tabular}{|c|c|c|c|c|c|c|c|c|}
\hline & $(1)$ & $(2)$ & $(3)$ & (4) & $(5)$ & (6) & $(7)$ & $(8)$ \\
\hline $\log \left(\right.$ No. Estab. $/$ mi. $\left.^{2}\right)$ & $\begin{array}{l}0.1741^{*} \\
(0.0178)\end{array}$ & & & & $\begin{array}{l}0.2122^{*} \\
(0.0177)\end{array}$ & & & \\
\hline $\log \left(\right.$ No. Firms $/$ mi. $\left.^{2}\right)$ & & $\begin{array}{l}0.1481^{*} \\
(0.0190)\end{array}$ & & & & $\begin{array}{l}0.2294^{*} \\
(0.0218)\end{array}$ & & \\
\hline $\log \left(\right.$ HHI No. Estab./mi. $\left.{ }^{2}\right)$ & & & $\begin{array}{l}0.1512^{*} \\
(0.0179)\end{array}$ & & & & $\begin{array}{l}0.2165^{*} \\
(0.0187)\end{array}$ & \\
\hline $\log \left(\right.$ HHI No. Firms $\left./ \mathrm{mi}^{2}\right)$ & & & & $\begin{array}{c}0.1014^{*} \\
(0.0199)\end{array}$ & & & & $\begin{array}{c}0.2637^{*} \\
(0.0322)\end{array}$ \\
\hline Observations (rounded) & 7400 & 7400 & 7400 & 7400 & 7400 & 7400 & 7400 & 7400 \\
\hline Clusters (rounded) & 300 & 300 & 300 & 300 & 300 & 300 & 300 & 300 \\
\hline$R^{2}$ & 0.0779 & 0.0625 & 0.0737 & 0.0473 & & & & \\
\hline First-Stage F & & & & & 344.5 & 196.3 & 171.4 & 48.7 \\
\hline$p$ Value & & & & & 0 & 0 & 0 & 0 \\
\hline Hansen J Statistic & & & & & 4.639 & 7.481 & 3.153 & 5.702 \\
\hline$p$ Value & & & & & 0.0983 & 0.0237 & 0.2067 & 0.0578 \\
\hline
\end{tabular}

Notes: Here I present OLS and IV results for the effect of competition on labor productivity residuals, as discussed in Section A.2.3 Models (1)-(4) and (5)-(8) use the four distinct competition measures indicated on the left. Year-specific constants are included but not reported and standard errors (in parentheses) are clustered at the CEA level. Instruments for models (5)-(8) are the number of building permits per square mile, the number of single family building permits per square mile, and local government road and highway expenditure per square mile. First-stage F tests and Hansen J (over identification) test statistics are reported with associated p values. For reference, ${ }^{*}$ signifies $p \leq 0.05$. 
Table A-5: Labor Productivity: Grouped Quantile IV

\begin{tabular}{lcccccccccc}
\hline & \multicolumn{1}{c}{ Dependent Variable: $w_{i t}$} \\
& $(1)$ & $(2)$ & $(3)$ & $(4)$ & $(5)$ & $(6)$ & $(7)$ & $(8)$ & $(9)$ \\
\hline $\log \left(\right.$ No. Estab./mi. $\left.{ }^{2}\right)$ & $0.1731^{*}$ & $0.1774^{*}$ & $0.1811^{*}$ & $0.1987^{*}$ & $0.2019^{*}$ & $0.2011^{*}$ & $0.2105^{*}$ & $0.2326^{*}$ & $0.2720^{*}$ \\
& $(0.0288)$ & $(0.0256)$ & $(0.0235)$ & $(0.0217)$ & $(0.0216)$ & $(0.0240)$ & $(0.0242)$ & $(0.0262)$ & $(0.0319)$ \\
$\log \left(\right.$ No. Firms $\left./ \mathrm{mi.}^{2}\right)$ & $0.1734^{*}$ & $0.1763^{*}$ & $0.1807^{*}$ & $0.1967^{*}$ & $0.2007^{*}$ & $0.2012^{*}$ & $0.2103^{*}$ & $0.2308^{*}$ & $0.2676^{*}$ \\
& $(0.0284)$ & $(0.0256)$ & $(0.0239)$ & $(0.0220)$ & $(0.0221)$ & $(0.0246)$ & $(0.0247)$ & $(0.0270)$ & $(0.0334)$ \\
$\log \left(\right.$ HHI No. Estab. $/$ mi. $\left.^{2}\right)$ & $0.1626^{*}$ & $0.1682^{*}$ & $0.1711^{*}$ & $0.1890^{*}$ & $0.1915^{*}$ & $0.1898^{*}$ & $0.1993^{*}$ & $0.2209^{*}$ & $0.2591^{*}$ \\
& $(0.0274)$ & $(0.0243)$ & $(0.0220)$ & $(0.0203)$ & $(0.0202)$ & $(0.0224)$ & $(0.0226)$ & $(0.0245)$ & $(0.0299)$ \\
$\log \left(\right.$ HHI No. Firms $/$ mi. $\left.^{2}\right)$ & $0.1725^{*}$ & $0.1761^{*}$ & $0.1805^{*}$ & $0.1972^{*}$ & $0.2010^{*}$ & $0.2012^{*}$ & $0.2101^{*}$ & $0.2305^{*}$ & $0.2682^{*}$ \\
& $(0.0287)$ & $(0.0258)$ & $(0.0239)$ & $(0.0220)$ & $(0.0222)$ & $(0.0248)$ & $(0.0248)$ & $(0.0271)$ & $(0.0336)$ \\
\hline Observations (rounded) & 900 & 900 & 900 & 900 & 900 & 900 & 900 & 900 & 900 \\
Clusters (rounded) & 300 & 300 & 300 & 300 & 300 & 300 & 300 & 300 & 300 \\
\hline
\end{tabular}

Notes: This table contains IV regression results for the effect of competition on deciles of the labor productivity residual distribution at the year-CEA level of aggregation, as discussed in Section 5.2 and, for labor productivity, Appendix Section A.2.3 Year-specific constants are included but not reported and standard errors (in parentheses) are clustered at the CEA level. Every cell represents an independent IV regression. By column, Model (k) corresponds to IV regressions with the $k^{t h}$ decile of the productivity residual distribution as a dependent variable. By row, regressions use the competition measure reported on the left. Instruments for all regressions are the number of building permits per square mile, the number of single family building permits per square mile, and local government road and highway expenditure per square mile. For reference, $*$ signifies $p \leq 0.05$.

Table A-6: Labor Productivity: Selection Correction

\begin{tabular}{lcccc}
\hline & \multicolumn{4}{c}{ Dependent Variable: $w_{i t}$} \\
& $(1)$ & $(2)$ & $(3)$ & $(4)$ \\
\hline $\log \left(\right.$ No. Estab./mi. $\left.{ }^{2}\right)$ & $0.2468^{*}$ & & & \\
& $(0.0241)$ & & & \\
$\log \left(\right.$ No. Firms/mi. $\left.{ }^{2}\right)$ & & $0.2887^{*}$ & & \\
& & $(0.0232)$ & & \\
$\log ($ HHI No. Estab./mi. & \\
& & & $0.2876^{*}$ & \\
$\log \left(\right.$ HHI No. Firms $/$ mi. $\left.^{2}\right)$ & & & $(0.0493)$ & \\
& & & & $0.3032^{*}$ \\
Selection Coeff $\left(\alpha_{c}\right)$ & -0.0059 & -0.0163 & -0.0124 & 0.0042 \\
& $(0.0099)$ & $(0.0142)$ & $(0.0527)$ & $(0.0173)$ \\
\hline Observations (rounded) & 3100 & 3100 & 3100 & 3100 \\
Clusters (rounded) & 300 & 300 & 300 & 300 \\
Hansen J Statistic & 11.850 & 20.180 & 18.010 & 6.001 \\
$\quad p$ Value & 0.0185 & 0.0005 & 0.0012 & 0.1991 \\
\hline
\end{tabular}

Notes: This table presents results for the semi-parametric selection correction procedure detailed in Section 5.1 using four different indices for competition, and labor productivity in place of $\omega_{i t}$. Year-specific constants are included but not reported and standard errors (in parentheses) are clustered at the CEA level. For reference, ${ }^{*}$ signifies $p \leq 0.05$.

\section{A.2.4 Robustness: Second-Order Markov Process}

Here I recast the semi-parametric estimation strategy of Section 5.1 where Assumption 2 is weakened to allow for a second-order Markov process. 
Table A-7: Second-Order Markov Process

\begin{tabular}{lcccc}
\hline & $(1)$ & Dependent Variable: $w_{i t}$ \\
& 0.0290 & $(3)$ & $(4)$ \\
\hline $\log \left(\right.$ No. Estab. $/$ mi. $\left.^{2}\right)$ & $(0.0154)$ & & & \\
& & 0.0235 & & \\
$\log \left(\right.$ No. Firms $/$ mi. $\left.^{2}\right)$ & & $(0.0168)$ & & \\
& & & $0.0314^{*}$ & \\
$\log \left(\right.$ HHI No. Estab. $/$ mi. $\left.^{2}\right)$ & & & $(0.0151)$ & \\
& & & & 0.0315 \\
$\log \left(\right.$ HHI No. Firms $/$ mi. $\left.^{2}\right)$ & & & $0.0190)$ \\
& & & & \\
Selection Coeff $\left(\alpha_{c}\right)$ & 0.0054 & 0.0094 & 0.0044 & 0.0097 \\
& $(0.0052)$ & $(0.0066)$ & $(0.0050)$ & $(0.0073)$ \\
\hline Observations (rounded) & 1000 & 1000 & 1000 & 1000 \\
Clusters (rounded) & 250 & 250 & 250 & 250 \\
Hansen J Statistic & 10.550 & 9.328 & 10.770 & 8.827 \\
$\quad p$ Value & 0.4814 & 0.5916 & 0.4620 & 0.6378 \\
\hline
\end{tabular}

Notes: This table presents results for the semi-parametric selection correction procedure detailed in Section 5.1 using four different indices for competition, extended as described in Appendix Section A.2.4 to allow for a second-order Markov process for the innovation in productivity residuals. Year-specific constants are included but not reported and standard errors (in parentheses) are clustered at the CEA level. For reference, ${ }^{*}$ signifies $p \leq 0.05$.

\section{A.3 Mechanisms: Management and Organizational Practices Data}

One direction for understanding the within-firm effects I document here is to look for evidence directly in management practices. This is particularly difficult for lack of data. Here I take advantage of unique data collected in partnership with the Census and documented by Bloom et al. (2017).

The MOPS survey is a survey of management and IT practices that accompanied the 2010 Annual Survey of Manufacturers. It included a large set of questions that covered topics on incorporation of management practices, incentive schemes, and information technology.

My design follows Section 6.4: I ask whether exogenous changes in market competitiveness, driven by changes in market size, are correlated with changes in management practices as measured by the monotized scores (between 0 and 1) for each subsection of the survey. Those scores aggregate all of the questions in each area of the survey, see Bloom et al. (2017) for details.

Results are presented in Table A-8, Disappointingly, for none of the survey areas do I find any statically significant effects — in fact, point estimates are counter-intuitively negative. 
Table A-8: Management and Organizational Practices Survey (MOPS) Data

\begin{tabular}{|c|c|c|c|c|c|c|}
\hline & \multicolumn{6}{|c|}{ Dependent Variable: } \\
\hline & \multicolumn{2}{|c|}{ Management Score } & \multicolumn{2}{|c|}{ Monitoring Score } & \multicolumn{2}{|c|}{ Incentives Score } \\
\hline & (1) & $(2)$ & $(3)$ & $(4)$ & $(5)$ & $(6)$ \\
\hline $\log \left(\right.$ No. Estab. $\left./ \mathrm{mi}^{2}{ }^{2}\right)$ & $\begin{array}{l}-0.0071 \\
(0.0084)\end{array}$ & & $\begin{array}{l}-0.0072 \\
(0.0088)\end{array}$ & & $\begin{array}{l}-0.0087 \\
(0.0105)\end{array}$ & \\
\hline $\log \left(\right.$ No. Firms. $/$ mi. $\left.^{2}\right)$ & & $\begin{array}{c}-0.0068 \\
(0.0083)\end{array}$ & & $\begin{array}{c}-0.0066 \\
(0.0089)\end{array}$ & & $\begin{array}{c}-0.0088 \\
(0.0105)\end{array}$ \\
\hline Observations (rounded) & 1000 & 1000 & 1000 & 1000 & 1000 & 1000 \\
\hline Clusters (rounded) & 250 & 250 & 250 & 250 & 250 & 250 \\
\hline First-Stage F & 128.9 & 82.52 & 128.9 & 82.52 & 128.9 & 82.52 \\
\hline$p$ Value & 0 & 0 & 0 & 0 & 0 & 0 \\
\hline Hansen J Statistic & 0.3653 & 0.4202 & 2.3090 & 2.407 & 0.0216 & 0.0125 \\
\hline$p$ Value & 0.5456 & 0.5168 & 0.1286 & 0.1207 & 0.8831 & 0.9111 \\
\hline
\end{tabular}

Notes: Here I consider alternative specifications of the IV regressions with left-hand side variables constructed from the MOPS survey, as detailed in Section A.3 This sample is independent of that used in other tables: it is made up of RMC firms sampled in the 2010 ASM that filled out the MOPS survey. Standard errors (in parentheses) are clustered at the CEA level. Instruments include the number of building permits per square mile, the number of single family building permits per square mile, and local government road and highway expenditure per square mile. For reference, ${ }^{*}$ signifies $p \leq 0.05$.

I conjecture that the questions of the survey are better designed to think about management in large-scale organizations, where questions of delegation, agency, and monitoring are paramount. Most of the RMC plants in my sample (though fewer in 2010) are owneroperated, and therefore the management concerns they face are likely to be rather different, from labor practices (especially hiring) to scheduling and coordination. This would be more consistent with the evidence of specialization and managerial inputs documented in Section 6.4 .

\section{A.4 Monte Carlo Exercise}

Here I construct a simple Monte Carlo exercise to replicate the order statistic bias discussed in Section 5.2.2. In my sample there are 300 markets. In each market there are a handful of firms, distributed $1+X$, where $X$ is exponential with parameter $\lambda=10$. Moreover, each market has a geographic area that is distributed exponential with parameter $\lambda=12,000$. Firms have productivity draws that are iid $N(0,0.27)$.

With this I can construct (exact) quantiles of the productivity distribution at the market level, as well as the log number of establishments per square mile, my dependent variable. 
Table A-9: Monte Carlo Exercise in Progress

\begin{tabular}{|c|c|c|c|c|c|c|c|c|c|}
\hline & \multicolumn{9}{|c|}{ Dependent Variable: $\rho_{m t}^{(k)}$} \\
\hline & (1) & (2) & (3) & (4) & (5) & (6) & (7) & (8) & (9) \\
\hline \multicolumn{10}{|l|}{ Uncorrected: } \\
\hline Estimate & $\begin{array}{c}-0.0338 \\
(0.0073)\end{array}$ & $\begin{array}{c}-0.0163 \\
(0.0065)\end{array}$ & $\begin{array}{c}-0.0072 \\
(0.0063)\end{array}$ & $\begin{array}{c}-0.0024 \\
(0.0063)\end{array}$ & $\begin{array}{c}0.0060 \\
(0.0061)\end{array}$ & $\begin{array}{c}0.0029 \\
(0.0059)\end{array}$ & $\begin{array}{c}0.0076 \\
(0.0063)\end{array}$ & $\begin{array}{l}0.0178 \\
0.0066\end{array}$ & $\begin{array}{l}0.0340 \\
0.0079\end{array}$ \\
\hline CI Length & $\begin{array}{c}0.0274 \\
(0.0017)\end{array}$ & $\begin{array}{c}0.0245 \\
(0.0017)\end{array}$ & $\begin{array}{c}0.0226 \\
(0.0016)\end{array}$ & $\begin{array}{c}0.0217 \\
(0.0016)\end{array}$ & $\begin{array}{c}0.0217 \\
(0.0016)\end{array}$ & $\begin{array}{c}0.0217 \\
(0.0015)\end{array}$ & $\begin{array}{c}0.0228 \\
(0.0015)\end{array}$ & $\begin{array}{l}0.0240 \\
0.0017\end{array}$ & $\begin{array}{l}0.0272 \\
0.0018\end{array}$ \\
\hline Coverage Rate & 0.0000 & 0.2200 & 0.7700 & 0.8900 & 0.7800 & 0.9000 & 0.7200 & 0.2000 & 0.0000 \\
\hline \multicolumn{10}{|l|}{ Corrected: } \\
\hline Estimate & $\begin{array}{c}-0.0006 \\
(0.0080)\end{array}$ & $\begin{array}{c}-0.0013 \\
(0.0075)\end{array}$ & $\begin{array}{c}-0.0013 \\
(0.0077)\end{array}$ & $\begin{array}{c}-0.0008 \\
(0.0078)\end{array}$ & $\begin{array}{c}-0.0010 \\
(0.0076)\end{array}$ & $\begin{array}{c}0.0004 \\
(0.0068)\end{array}$ & $\begin{array}{c}0.0018 \\
(0.0064)\end{array}$ & $\begin{array}{l}0.0022 \\
0.0067\end{array}$ & $\begin{array}{l}0.0017 \\
0.0077\end{array}$ \\
\hline CI Length & $\begin{array}{c}0.0311 \\
(0.0025)\end{array}$ & $\begin{array}{c}0.0299 \\
(0.0025)\end{array}$ & $\begin{array}{c}0.0285 \\
(0.0025)\end{array}$ & $\begin{array}{c}0.0276 \\
(0.0024)\end{array}$ & $\begin{array}{c}0.0274 \\
(0.0024)\end{array}$ & $\begin{array}{c}0.0276 \\
(0.0024)\end{array}$ & $\begin{array}{c}0.0288 \\
(0.0024)\end{array}$ & $\begin{array}{l}0.0296 \\
0.0025\end{array}$ & $\begin{array}{l}0.0310 \\
0.0025\end{array}$ \\
\hline Coverage Rate & 0.9500 & 0.9500 & 0.9500 & 0.9200 & 0.9200 & 0.9700 & 0.9700 & 0.9900 & 0.9500 \\
\hline F Test p-Value & $\begin{array}{c}0.0000 \\
(0.0000)\end{array}$ & $\begin{array}{c}0.0031 \\
(0.0159)\end{array}$ & $\begin{array}{c}0.2394 \\
(0.2843)\end{array}$ & $\begin{array}{c}0.4370 \\
(0.2993)\end{array}$ & $\begin{array}{c}0.3002 \\
(0.2864)\end{array}$ & $\begin{array}{c}0.4969 \\
(0.3063)\end{array}$ & $\begin{array}{c}0.2038 \\
(0.2608)\end{array}$ & $\begin{array}{l}0.0187 \\
0.0606\end{array}$ & $\begin{array}{l}0.0000 \\
0.0000\end{array}$ \\
\hline
\end{tabular}

Notes: This table presents results for the Monte Carlo simulation of the correction for order statistic bias. Means and standard deviations (the latter in parentheses) are reported for the parameter estimate, the length of the confidence interval, and the coverage rate, for both the uncorrected and the corrected estimates. Finally, at the bottom of the table, I report the $\mathrm{p}$ value for the $\mathrm{F}$ test corresponding to the joint significance of the coefficients on the polynomial series.

Since the latter is generated independently of productivity draws, I use OLS estimates in the estimation exercise. I estimate two versions: a straw man version, without any bias correction, and a version with a fifth-degree polynomial series in the number of firms in the market. Each regression is run 10,000 times. Note that the true parameter $\beta_{c}$ in this exercise is equal to zero.

Results are presented in Table A-9 for each decile of the productivity distribution. For each parameters I present the mean and standard deviation (the latter in parentheses).

As expected, we see a strong negative bias in the lower deciles and a positive bias in the upper deciles for the uncorrected estimator. Confidence intervals are narrow (between 0.21 and 0.28 ), and so coverage drops to zero in these regions. It is better, although still shy of 0.95 for deciles $4-6$. The picture is better for the corrected estimator. Although confidence intervals are between 10 and $20 \%$ wider, the coverage is restored to the neighborhood 0.95 for all deciles, and estimates are close to zero. Finally, at the bottom of Table A-9 I report the average $\mathrm{p}$ value for the $\mathrm{F}$ test corresponding to the joint significance of the coefficients on the polynomial series. We expect this to be close to zero when the bias correction is doing 
more work, and indeed, this is what we see for the extremal deciles.

\section{B Theoretical Motivation}

Consider the following variation on an entry game. In the first stage of the game there is an infinite mass of potential entrants. They are ex-ante identical; potential entrants do not know their type, but they do have rational expectations. If they enter, they pay a cost of entry $c_{e}$. Let $\lambda$ denote the endogenous mass of entrants in state 1 . In the second stage entrants learn their idiosyncratic types, denoted $\phi$, which are distributed i.i.d. according to a continuous distribution $G$ on $[0,1]$. At this point they make a second choice. They may exit or stay active; if they exit they receive a payoff normalized to zero. Let $\mu$ denote the measure of active, non-exiting firms on the type space $[0,1]$. Those firms make obtain profits given by $\pi(\phi, C(\mu), D)$, where $D$ is a demand shifter and $C$ is a continuous function mapping measures $\mu$ into $\mathbb{R}$. C represents an ideal competition index. I assume that $C$ is increasing in the following partial order: if $\mu \geq \mu^{\prime}$ on $[0,1]$ and $\mu^{\prime}>\mu$ for some open set in $[0,1]$ then $C\left(\mu^{\prime}\right)>C(\mu)$. I also assume that $\pi$ is continuously differentiable in all of its arguments, strictly increasing in $\phi$ and $D$, and strictly decreasing in the same partial order on $C$.

This model is in the spirit of Hopenhayn (1992) and Asplund and Nocke (2006), however I have abstracted away from dynamics for simplicity. Consistent with those models, monotonicity of $\pi$ implies that the exit decision in the second stage follows a threshold rule; let us call it $\bar{\phi}$. An equilibrium is a pair $\langle\lambda, \bar{\phi}>$ such that:

$$
\begin{gathered}
\int_{\phi^{*}}^{1} \pi(\phi, C(\mu), D) d G(\phi)=c_{e} \\
\pi(\bar{\phi}, C(\mu), D) d G(\phi)=0
\end{gathered}
$$

Equilibrium condition (E1) reflects optimal choice by potential entrants ex ante, while condition (E2) reflects the ex post exit choice of entrant firms. First, lets note that a nontrivial equilibrium exists and is unique under mild conditions.

Proposition 1. Let $\psi \equiv\{\phi: \pi(\phi, C(0), D)=0\}$. If

1. $\int_{\psi}^{1} \pi(\phi, C(0), D) d G(\phi)>c_{e}$, and

Appendix-9 
2. there exists a finite measure $\tilde{\mu}$ on $[0,1]$ such that $\pi(1, C(\tilde{\mu}), D)<0$,

then there exists a unique equilibrium with a nonempty market (i.e., such that $\mu \neq 0$ ).

Proof. I omit the proof of existence, which follows directly from Conditions 1 and 2 and application of the Schauder Fixed Point theorem.

To see uniqueness, suppose by way of contradiction that there were two equilibria at $<\lambda, \bar{\phi}>$ and $\left\langle\lambda^{\prime}, \bar{\phi}^{\prime}>\right.$. From (E2), we have $\bar{\phi}^{\prime}>\phi \Leftrightarrow \lambda^{\prime}>\lambda$. Suppose without loss of generality that $\bar{\phi}^{\prime}>\bar{\phi}$. However, now $\int_{\bar{\phi}^{\prime}}^{1} \pi\left(\phi, C\left(\mu^{\prime}\right), D\right)<\int_{\bar{\phi}}^{1} \pi(\phi, C(\mu), D) d G(\phi)=c_{e}$, which contradicts the claim that $\left\langle\lambda^{\prime}, \bar{\phi}^{\prime}\right\rangle$ is an equilibrium.

The key result is a comparative static in $D$, which stands in for demand shifters. I am interested in showing how the optimal threshold $\bar{\phi}$ moves as the market size grows. In order to prove this I need two more assumptions. The first is an innocuous assumption that says that when the market grows, the profits of high type firms grow no less than proportionately.

Assumption 3. For $\phi^{\prime}>\phi, D^{\prime}>D$, and any $C$,

$$
\frac{\pi\left(\phi^{\prime}, C, D^{\prime}\right)}{\pi\left(\phi, C, D^{\prime}\right)} \geq \frac{\pi\left(\phi^{\prime}, C, D\right)}{\pi(\phi, C, D)} .
$$

The second assumption is more critical, and embodies the reallocation hypothesis:

Assumption 4. For $\phi^{\prime}>\phi, C^{\prime}>C$, and any $D$,

$$
\frac{\pi\left(\phi^{\prime}, C^{\prime}, D^{\prime}\right)}{\pi\left(\phi, C^{\prime}, D\right)}>\frac{\pi\left(\phi^{\prime}, C, D\right)}{\pi(\phi, C, D)} .
$$

This assumption is critical to the selection hypothesis. On the theory side, Asplund and Nocke (2006) argue that it is consistent with many standard models. Going a step further, Boone (2008) argues that this is in fact constitutive of our very idea of competition. Finally this mechanism has become central in trade and productivity analysis literatures as well. In Proposition 2 I show that it implies the selection effect hypothesis.

Proposition 2. If $D^{\prime} \geq D$, then $\bar{\phi}^{\prime} \geq \bar{\phi}$ 
Proof. First, note that $C\left(\mu^{\prime}\right) \geq C(\mu)$. Suppose, by way of contradiction, otherwise. Then (E2) implies that $\bar{\phi}^{\prime}<\bar{\phi}$. Now, $\int_{\bar{\phi}^{\prime}}^{1} \pi\left(\phi, C\left(\mu^{\prime}\right), D^{\prime}\right)>\int_{\phi^{*}}^{1} \pi(\phi, C(\mu), D) d G(\phi)=c_{e}$, which generates a contradiction.

Next observe that, for (E1) to hold, there must exist $\tilde{\phi}$ such that $\pi\left(\tilde{\phi}, C\left(\mu^{\prime}\right), D^{\prime}\right)=\pi(\tilde{\phi}, C(\mu), D)>$ 0. Moreover, for $\phi^{\prime}<\tilde{\phi}$,

$$
\begin{aligned}
& \frac{\pi\left(\phi^{\prime}, C\left(\mu^{\prime}\right), D^{\prime}\right)}{\pi\left(\tilde{\phi}, C\left(\mu^{\prime}\right), D^{\prime}\right)}<\frac{\pi\left(\phi^{\prime}, C(\mu), D\right)}{\pi(\tilde{\phi}, C(\mu), D)} \\
& \quad \Rightarrow \pi\left(\phi^{\prime}, C\left(\mu^{\prime}\right), D^{\prime}\right)<\pi\left(\phi^{\prime}, C(\mu), D\right) .
\end{aligned}
$$

The first line follows from $\log$ increasing differences and the complementarity of $D$ and $C(\mu)$. The second line follows from $\pi\left(\tilde{\phi}, C\left(\mu^{\prime}\right), D^{\prime}\right)=\pi(\tilde{\phi}, C(\mu), D)>0$, and implies that $\bar{\phi}^{\prime}<\bar{\phi}$. 